\title{
Decreased TLR3 in Hyperplastic Adipose Tissue, Blood and Inflamed Adipocytes is Related to Metabolic Inflammation
}

\author{
Jèssica Latorre ${ }^{a, b, c}$ José M. Moreno-Navarrete ${ }^{a, b, c}$ Mónica Sabater ${ }^{a, b, c} \quad$ Maria Buxo $^{b}$ \\ José I. Rodriguez-Hermosa ${ }^{b, d} \quad$ Jordi Girones ${ }^{b, d} \quad$ José M. Forte Ramón Vilallongae \\ Wifredo Ricart ${ }^{a, b, c} \quad$ Rafael Simo ${ }^{f}$ José M. Fernández-Real ${ }^{a, b, c} \quad$ Francisco J. Ortega ${ }^{a, b, c}$ \\ ${ }^{a}$ CIBEROBN and Instituto de Salud Carlos III (ISCIII) - Madrid, 'Institut d'Investigació Biomédica de \\ Girona (IdIBGi) - Girona, 'Department of Diabetes, Endocrinology and Nutrition (UDEN), Hospital of \\ Girona "Dr Josep Trueta" - Girona, "Department of Surgery, Hospital of Girona "Dr Josep Trueta" - \\ Girona, eMetabolic and Bariatric Surgery Unit, Hospital Universitario Vall d'Hebron, European Center \\ of Excellence (EAC-BS) - Barcelona, 'Diabetes and Metabolism Research Unit, Vall d'Hebron Research \\ Institute, Universitat Autònoma de Barcelona, CIBERDEM and Instituto de Salud Carlos III (ISCIII) - \\ Barcelona, Spain
}

\section{Key Words}

Toll-like receptors $\cdot$ Gene expression $\cdot$ Macrophages $\cdot$ Adipocytes $\cdot$ Adipose tissue $\cdot$ Blood - Innate immune system - Obesity - Inflammation - Insulin resistance - Type 2 diabetes • Humans

\begin{abstract}
Background/Aims: Obesity is characterized by the immune activation that eventually dampens insulin sensitivity and changes metabolism. This study explores the impact of different inflammatory/ anti-inflammatory paradigms on the expression of toll-like receptors (TLR) found in adipocyte cultures, adipose tissue, and blood. Methods: We evaluated by real time PCR the impact of acute surgery stress in vivo (adipose tissue) and macrophages (MCM) in vitro (adipocytes). Weight loss was chosen as an anti-inflammatory model, so TLR were analyzed in fat samples collected before and after bariatric surgery-induced weight loss. Associations with inflammatory and metabolic parameters were analyzed in non-obese and obese subjects, in parallel with gene expression measures taken in blood and isolated adipocytes/ stromal-vascular cells (SVC). Treatments with an agonist of TLR3 were conducted in human adipocyte cultures under normal conditions and upon conditions that simulated the chronic low-grade inflammatory state of obesity. Results: Surgery stress raised TLR1 and TLR8 in subcutaneous (SAT), and TLR2 in SAT and visceral (VAT) adipose tissue, while decreasing VAT TLR3 and TLR4. MCM led to increased TLR2 and diminished TLR3, TLR4, and TLR5 expressions in human adipocytes. The anti-inflammatory impact of weight loss was concomitant with

\footnotetext{
J.M. Fernandez-Real, M.D., Ph.D. Department of Diabetes, Endocrinology and Nutrition (UDEN), Institut d'Investigació Biomédica de and F.J. Ortega, Ph.D. Tel. +34 6288614 78, Fax +34 9729402 70, E-Mail jmfreal@idibgi.org; fortega@idibgi.org
} 
decreased TLR1, TLR3, and TLR8 in SAT. Cross-sectional associations confirmed increased V/ SAT TLR1 and TLR8, and decreased TLR3 in obese patients, as compared with non-obese subjects. As expected, TLR were predominant in SVC and adipocyte precursor cells, even though expression of all of them but TLR8 (very low levels) was also found in ex vivo isolated and in vitro differentiated adipocytes. Among SVC, CD14+ macrophages showed increased TLR1, TLR2, and TLR7, but decreased TLR3 mRNA. The opposite patterns shown for TLR2 and TLR3 in V/ SAT, SVC, and inflamed adipocytes were observed in blood as well, being TLR3 more likely linked to lymphocyte instead of neutrophil counts. On the other hand, decreased TLR3 in adipocytes challenged with MCM dampened lipogenesis and the inflammatory response to Poly $(\mathrm{l}: \mathrm{C})$. Conclusion: Functional variations in the expression of TLR found in blood and hypertrophied fat depots, namely decreased TLR3 in lymphocytes and inflamed adipocytes, are linked to metabolic inflammation.

(C) 2018 The Author(s)

Published by S. Karger AG, Basel

\section{Introduction}

Toll-like receptors (TLR) are evolutionarily conserved receptors that play a key role in the innate immune response to invading pathogens, by sensing either microorganism or danger signals [1]. TLR are also related to non-infectious inflammatory conditions, such as obesity and the initiation and maintenance of innate immune responses conducted in obese adipose tissue (AT) [2,3]. In fact, the obesity-related frame of low-grade inflammation is often observed in metabolic diseases, and is believed to be due to the increased gut permeability and the impact of structural motifs released by microbial pathogens that may activate TLR found in circulation [4-6] and AT depots [7]. Thereby, specific cargo of different TLR found in blood immune cells and adipocytes may change peripheral metabolism, responding to different pathogen associated molecular patterns and promoting the shift from anabolic to catabolic processes aimed at providing with energy the immune system [8,9].

Signaling by TLR results in a large variety of cellular responses including (but not limited to) the production of cytokines and chemokines responsible of the inflammatory reaction and immune attack against infection [10]. Stimulation of TLR by the corresponding molecular motifs initiates signaling cascades leading to the activation of transcription factors and other molecules involved in inflammation [11]. Overall, TLR activate adapter proteins that lead to $\mathrm{NF} \kappa \mathrm{B}$ signaling after the formation of IL-1R-associated kinase (IRAK)1, IRAK-4, tumor necrosis factor associated factor (TRAF)-6, and IKB complexes [12]. TLR1 is an important paralog of TLR6 that shows heterodimerization with TLR2 and the transmembrane signaling receptor activity that mediates innate immune responses to bacterial lipopeptides, leading to the inflammatory reaction, $\mathrm{NF} \kappa \mathrm{B}$ activation, and cytokine secretion [13]. TLR2 is essential for recognition of Gram-positive bacteria through detection of bacterial lipoproteins, lipomannans and lipoteichoic acids [14], and has been reported as closely associated with insulin resistance and $\beta$-cell dysfunction $[15,16]$, including the overexpression found in AT and peripheral blood mononuclear cells from obese and diabetic patients, together with TLR4 [17]. TLR3 is implicated in virus-derived doublestranded RNA, is highly expressed in pancreatic $\beta$-cells, and has been functionally related to metabolic inflammation and impaired glucose tolerance through a TLR3 knock-out mice model [18]. Also TLR4, being predominantly activated by lipopolysaccharide [19], may be linked to the negative impact of elevated levels of free fatty acids and the activation of the immunometabolic regulatory capacity of pathogen-sensing systems downstream NFKB under non-pathological circumstances [20,21], leading to metabolic inflammation [22]. Endorsing this observation, TLR4-deficient mice showed protection against diet-induced obesity and insulin resistance [23], while polymorphisms affecting human TLR4 have been linked to the risk of type 2 diabetes [24]. On their side, TLR5 detects bacterial flagellin [25], dimers of TLR6 and TLR2 or TLR4 are required for conducting the response to lipoproteins during metabolic endotoxemia [26], TLR9 is important for the recognition of unmethylated CpG DNA [27], and TLR7 and TLR8 can intercept single and short double-stranded RNA 
molecules released within the endosomal compartments [25], being mostly responsible for the proinflammatory cytokines that are secreted by activated monocytes and lymphocytes $[28,29]$. In consensus with such inflammatory signatures and immune activation, elevated AT expression of TLR8 has been also reported in metabolically compromised subjects [30]. Finally, TLR10 has been considered the only orphan human TLR, with no confirmed ligand nor biological function until the findings of Song Jiang and coworkers, supporting the idea that TLR10 may display some anti-inflammatory properties [31], and the approach recently performed in human AT by Syndhu et al. [32], suggestive of a relationship with metabolic inflammation.

Over the last years, the constant flow of clinical and experimental data has provided insights pointing at the interrelationship between enlarged fat depots, activated innate immunity, enhanced inflammation, impaired metabolism, systemic insulin resistance, and increased risk of type 2 diabetes in obese patients [33]. However, the immunometabolic capacity of pathogen-sensing systems activated in obesity is still not fully understood [13, 34]. Here, we have conducted four association studies trying to identify variations in TLR gene expression that may alter risk of disease in obese patients. We first looked for TLR that were differentially expressed in the AT of morbid obese patients following surgeryinduced weight loss [35]. From an initial list of ten TLR, we focused on receptors that showed significant modulation after the anti-inflammatory effects of weight loss (i.e. TLR1-8). Then, we explored the effects of different inflammatory paradigms on the expression patterns of subcutaneous and visceral AT and whole blood. Among the former, we evaluated the effects of macrophage conditioned media in vitro (human adipocyte cultures) and acute surgery stress in vivo (human AT). We also assessed the associations of TLR with inflammatory parameters, expression measures taken in blood, and changes identified in ex vivo isolated adipocytes/ stromal-vascular cells. We report here decreased TLR3 in obese AT, blood and inflamed adipocytes, in parallel with immune and inflammatory cues that may impair metabolism in differentiated adipocytes, as further demonstrated by treatments with TLR3 agonists.

\section{Materials and Methods}

\section{Subject recruitment}

Selection of toll-like receptor (TLR) candidates was performed based on available transcriptomic profiling aimed at identify genes differentially expressed in human adipose tissue after weight loss. The study is described in detail elsewhere [35]. We focused our research on TLR that reported significant variations in this anti-inflammatory model (i.e. TLR1-8, Fig. 1A). Next, we explored the effects of different inflammatory paradigms on the expression patterns of subcutaneous (SAT) and visceral (VAT) adipose tissue and whole blood. Among the former, we evaluated the impact on TLR expression of acute surgery stress in vivo. Thereby, pre-post paired samples of SAT and VAT were obtained from 32 morbid obese women (body mass index $(\mathrm{BMI})=46.4 \pm 5.6 \mathrm{~kg} / \mathrm{m}^{2}$, age $=48 \pm 10$ years [mean $\pm \mathrm{SD}$ ]) following elective surgical procedures at the Department of General, Bariatric and Metabolic Surgery of the Hospital Universitari de la Vall d'Hebron (Barcelona, Spain), as previously explained [36]. We also evaluated cross-sectional associations of SAT and VAT TLR mRNAs with anthropometric, metabolic, immune, and inflammatory parameters in the hallmark of obesity-regulated genes in an extended sample of 80 subjects $\left(28 \%\right.$ men, $\mathrm{BMI}=38.9 \pm 7.3 \mathrm{~kg} / \mathrm{m}^{2}$, age $=47 \pm 12$ years) recruited at the Department of Diabetes, Endocrinology and Nutrition (UDEN), and the Department of Surgery of the Hospital of Girona "Dr Josep Trueta" (Girona, Spain). In parallel, $5 \mathrm{ml}$ of whole blood from 72 independent donors ( $27 \%$ men, $\mathrm{BMI}=38.8 \pm 11 \mathrm{~kg} / \mathrm{m}^{2}$, age $=47 \pm 10$ years $)$ were collected in PAXgene Blood RNA tubes (Qiagen, Hilden, Germany). The routine blood collection procedures were performed by a nurse of the Hospital of Girona "Dr Josep Trueta", after the research subject information and consent form was reviewed and approved by the corresponding committees. Samples and data from patients included in this study were partially provided by the FATBANK platform, promoted by the CIBEROBN, coordinated by the IDIBGI Biobank (Biobanc IDIBGI, B.0000872) and integrated in the Spanish National Biobanks Network, and were processed following standard operating procedures, including the appropriate approval of the Ethics, External Scientific and FATBANK Internal Scientific Committees. All participants were of Caucasian 


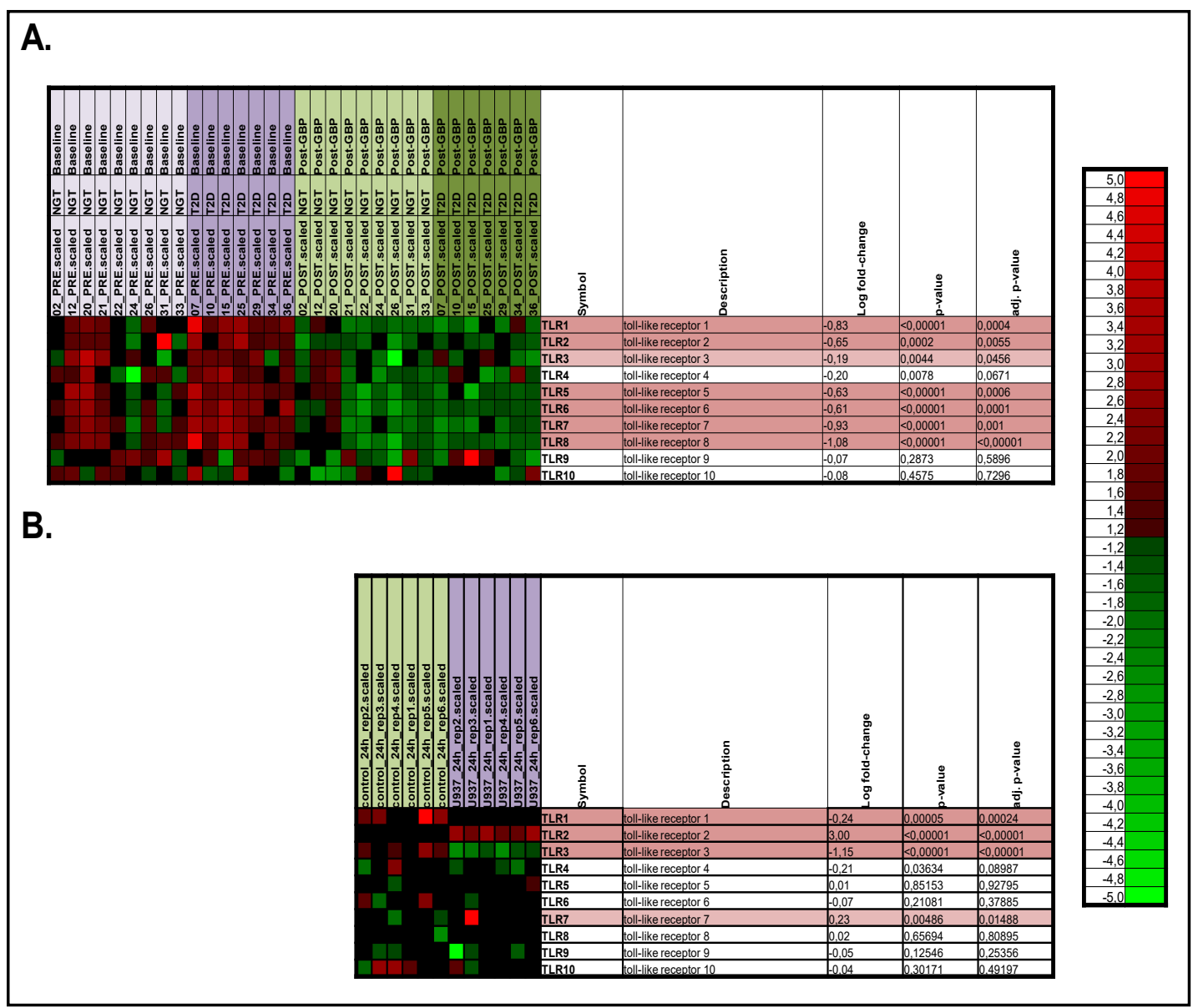

Fig. 1. A. Microarray results showing weight loss-associated changes in toll-like receptors (TLR) expressed in abdominal subcutaneous adipose tissue at the baseline and $\sim 2$-years after gastric bypass (Post-GBP) in 16 morbid obese women with normal glucose tolerance (NGT) or type 2 diabetes (T2D, n=7) [35]. B. Microarray results showing the impact of the macrophage LPS-conditioned media (14\%) in TLR expression by differentiated SGBS adipocytes [51].

origin, were free of any infections in the previous month and reported that their body weight has been stable for at least three months before entering the study. No systemic diseases other than type 2 diabetes (35\% of participants) and obesity were reported. Liver and thyroid dysfunction were specifically excluded by biochemical work-up. Other exclusion criteria included 1) clinically significant hepatic, neurological, or other major systemic disease, including malignancy, 2) history of drug or alcohol abuse, or serum transaminase activity more than twice the upper limit of normal, 3) an elevated serum creatinine concentration, 4) acute major cardiovascular event in the previous 6 months, 5) acute illnesses and current evidence of high grade chronic inflammatory or infective diseases, and 6) mental illness rendering the subjects unable to understand the nature, scope, and potential consequences of this study. We certify that all institutional regulations concerning the ethical use of information and samples from human subjects were followed during this research.

\section{Clinical measurements}

Body mass index (BMI) was calculated as weight (in kilograms) divided by height (in meters) squared. Percent fat mass was measured using the Tanita BIA scale (Tanita Corporation, Tokyo, Japan). Blood samples were drawn after an overnight fasting between 8:00 and 9:00 a.m. Glucose was measured with a glucose oxidase method using a Beckman Glucose Analyzer 2 (Beckman Instruments, Brea, CA). Lipid profile (triglycerides, total cholesterol, and high-density lipoprotein cholesterol (HDL) were measured by usual enzymatic methods on a Hitachi 917 instrument (Roche, Mannheim, Germany). HbA1c was measured by the

\section{KARGER}




\section{Cellular Physiology Cell Physiol Biochem 2018;51:1051-1068

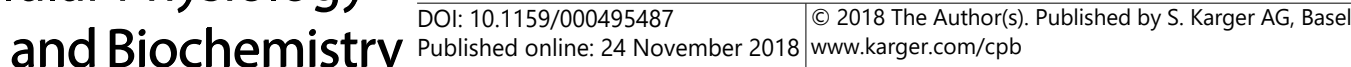

Latorre et al.: TLR3 and Metabolic Inflammation

high-performance liquid chromatography method (Bio-Rad, Muenchen, Germany). Intra-assay and interassay coefficients of variation were less than $4 \%$ for all these tests.

\section{Analyses in isolated AT cell fractions and experiments in vitro}

For analyses in isolated stoma-vascular cells (SVC) and mature adipocytes, $\sim 5 \mathrm{~g}$ of VAT and SAT from 32 obese women $\left(\mathrm{BMI}=43.2 \pm 6.3 \mathrm{~kg} / \mathrm{m}^{2}\right.$, age $=45 \pm 7$ years [mean $\pm \mathrm{SD}$ ]) were isolated and all visible connective tissue was removed. Finely minced samples went through a process of $1 \mathrm{~h}$ digestion at $37^{\circ} \mathrm{C}$ in a shaking water bath. The digestion buffer included $100 \mathrm{mM}$ HEPES containing $120 \mathrm{mM} \mathrm{NaCl}, 50 \mathrm{mM} \mathrm{KCl}, 5$ mM D-glucose, $1 \mathrm{mM} \mathrm{CaCl2,} \mathrm{1.5 \%} \mathrm{type-V} \mathrm{bovine} \mathrm{serum} \mathrm{albumin,} \mathrm{2 \%} \mathrm{penicillin/streptomycin} \mathrm{(Sigma} \mathrm{Aldrich,}$ St. Louis, M0), and $0.075 \%(1.5 \mathrm{mg} / \mathrm{ml})$ of Collagenase Type I solution (Worthington Biochemical Corp, Lakewood, NJ). The remaining procedures were similar to the previously described methods [37]. Upon disaggregation, digested AT tissue was centrifuged and cell fractions were collected in $20 \mathrm{ml}$ of PBS $2 \%$ penicillin/streptomycin. Then, cells were passed through sterile nylon mesh filters to remove any remaining tissue debris. Isolated SVC and adipocytes were centrifuged for $1 \mathrm{~min}$ at $400 \mathrm{~g}$ and water was withdrawn. CD14+ macrophages were isolated from other SVC in a subsample of 6 fat cell debris ( 3 from VAT and 3 from SAT depots) by means of magnetic cell isolation technology, according to the manufacturer's instructions (Miltenyi Biotec, Madrid, Spain). Cells and fat samples were stored at $-80^{\circ} \mathrm{C}$ until the subsequent analysis.

The human monocyte cell line THP-1 (ATCC, LGC Standards, Barcelona, Spain) was cultured in RPMI 1640 medium containing 10\% fetal bovine serum, $5 \mathrm{mM}$ glucose, $2 \mathrm{mM}$ L-glutamine, $50 \mathrm{mg} / \mathrm{ml}$ Gentamicin and $20 \mathrm{mM}$ HEPES at $37^{\circ} \mathrm{C}$ in a humidified $5 \% \mathrm{CO}_{2} / 95^{\circ} \mathrm{C}$ air atmosphere, as previously detailed [38]. The mature type 1 macrophage-like state was induced by $24 \mathrm{~h}$ of treatment with $0.162 \mathrm{mM}$ phorbol 12 -myristate 13-acetate (PMA, Sigma Chemical Co., St. Louis, MO). Differentiated plastic-adherent cells were washed with Dulbecco's phosphate-buffered saline solution (Sigma) and incubated with fresh medium without PMA. Then, differentiated M1 macrophages were incubated for $24 \mathrm{~h}$ in medium containing $10 \mathrm{ng} / \mathrm{ml}$ of lipopolysaccharide (LPS, Sigma). The LPS-stimulated macrophage conditioned media (MCM) was collected and centrifuged at $400 \mathrm{~g}$ for $5 \mathrm{~min}$, and diluted with adipocyte medium (ZenBio, Inc., Research Triangle Park, NC) to provide in adipocytes conditions aimed at simulate the chronic low-grade inflammatory state of obesity [35].

Human subcutaneous preadipocytes from a Caucasian male with BMI $<30 \mathrm{~kg} / \mathrm{m}^{2}$ and age $<40$ y (ZenBio, Research Triangle Park, NC) were cultured with the preadipocytes medium in a humidified $37^{\circ} \mathrm{C}$ incubator with $5 \% \mathrm{CO}_{2}$. Twenty-four hours after plating, cells were checked for complete confluence and differentiated using differentiation medium following manufacturer's instructions. Two weeks after the initiation of differentiation cells appeared rounded with large lipid droplets apparent in the cytoplasm, were considered differentiated mature adipocytes and were incubated with fresh adipocytes media as control, or fresh adipocytes media containing 2\% of MCM. After $24 \mathrm{~h}$ of treatment cells were harvested and stored at $-80^{\circ} \mathrm{C}$ for future analysis. The synthetic double-stranded RNA analog Poly(I:C) (Bio-Techne Europe Ltd., Abingdon, UK) was added to the media ( $20 \mu \mathrm{g} / \mathrm{ml}, 6 \mathrm{~h}$ of treatment $)$ in differentiated human adipocytes under normal conditions and after the MCM-induced inflammatory state of activation.

\section{RNA extraction and gene expression measures}

Total RNA was purified from blood, AT samples, and cell debris using miRNeasy® Mini Kit (QIAgen, Gaithersburg, MD). AT $(\sim 150 \mu \mathrm{g})$ and cells were homogenized in $0.6 \mathrm{ml}$ of QIAzol ${ }^{\circledR}$ Lysis Reagent (QIAgen). After addition of chloroform ( 0.4 volumes), the homogenate was separated into aqueous and organic phases by centrifugation ( $15 \mathrm{~min}$ at $12,000 \mathrm{~g}$ and $4^{\circ} \mathrm{C}$ ). Then, the upper aqueous RNA-rich phase was isolated and ethanol absolute (1.5 volumes) was added to provide appropriate binding conditions for RNA molecules. The sample was applied to the RNeasy® Mini spin column (QIAgen), where RNA binds to the membrane while phenols and other compounds are washed away. High quality RNA was finally eluted in $30 \mu$ of RNAsefree water. RNA concentrations were assessed with a Nanodrop ND-1000 Spectrophotometer (Thermo Fischer Scientific, Wilmington, DE). The integrity was checked with the Nano lab-on-a-chip assay for total eukaryotic RNA using Bioanalyzer 2100 (Agilent Technologies, Palo Alto, CA). Three $\mu$ g of RNA were reverse transcribed to cDNA using High Capacity cDNA® Archive Kit, according to the manufacturers' protocol (Applied Biosystems, Darmstadt, Germany). Commercially available and pre-validated TaqMan® primer/ probe sets were used for gene expression determinations (Applied Biosystems), which were assessed by real time PCR using the LightCycler $₫ 480$ Real-Time PCR System (Roche Diagnostics, Barcelona, Spain), and 


\section{Cellular Physiology Cell Physiol Biochem 2018;51:1051-1068

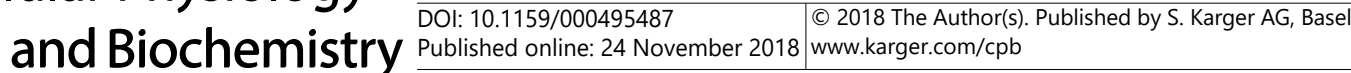

Latorre et al.: TLR3 and Metabolic Inflammation

the technology suitable for gene expression measures. The PCR reaction was performed in a final volume of $7 \mu \mathrm{l}$. The cycle program included an initial activation phase of $10 \mathrm{~min}$ at $95^{\circ} \mathrm{C}$ and 45 cycles of $15 \mathrm{sec}$ of denaturizing phase at $92^{\circ} \mathrm{C}$ and 1 min of annealing and cDNA extension at $60^{\circ} \mathrm{C}$. Crossing points (Cp) values were assessed for each amplification curve by the Second Derivative Maximum Method. $\Delta \mathrm{Cp}$ value was calculated by subtracting the $\mathrm{Cp}$ value of the corresponding endogenous controls (the peptidylprolyl isomerase A, also known as cyclophilin A) in each sample from the $\mathrm{Cp}$ value for each target gene. Fold changes compared to the endogenous control were determined by calculating the $2^{-\Delta C p}$, so gene expression results are expressed as expression ratio relative to this preselected and validated housekeeping. Replicates and positive and negative controls were included.

\section{Statistical methods}

Descriptive results of continuous variables are expressed as mean \pm standard deviation (in vivo assessment) or mean \pm standard error (in vitro measures). Before statistical analysis, normal distribution and homogeneity of variances were evaluated using Levene's test. ANOVA, Student's, or paired t-tests were performed to study differences on quantitative variables. The semi-quantitative expression of different TLR was correlated (Pearson's and/or Spearman's tests) with clinical parameters and the expression of other genes in human AT and blood. Statistical analyses were performed with the SPSS statistical software (SPSS V12.0, Inc., Chicago, IL).

\section{Results}

\section{Changes in AT TLR expression patterns during inflammation}

Wide transcriptomic profiling of abdominal subcutaneous adipose tissue (SAT) before and after weight loss [35] showed significant changes in 7 out of 10 toll-like receptors (TLR). Microarray measures pointed at TLR1 (-44\%), TLR2 (-36\%), TLR5 (-35\%), TLR6 (-34\%), TLR7 $(-47 \%)$, and TLR8 $(-53 \%)$ as the most significantly (adjusted $p$-value $<0.01)$ decreased TLR in human SAT upon weight loss (Fig. 1A). Slightly decreased TLR3 $(-12 \%$, adj. p-value $=0.046)$ was also identified, while AT TLR4 (adj. p-value=0.07), TLR9 and TLR10 failed in showing significant modulation upon bariatric surgery. Next, we investigated dynamic adaptations accounting during acute surgical stress in TLR showing significant modulation after weight loss. We tested the impact of acute surgical innate immune system activation leading to inflammation (i.e. increased expressions of IL-6, IL-8, TNF and LBP in fat depots [36]). The results supported distinct reactions in relation to surgical stress, confirming inflammatory mechanisms leading to changes in human TLR, as inferred by gene expression results in SAT and visceral (VAT) adipose tissue (Table 1). Increased TLR2 (1.6-fold, $\mathrm{p}=0.044$, and 2.1-fold change, $\mathrm{p}=0.003$, in SAT and VAT, respectively), and TLR1 (1.2-fold, $\mathrm{p}=0.047)$, TLR4 (1.2fold, $p=0.002$ ), and TLR8 (1.3-fold, $p=0.009$, only in SAT) mRNA was identified, while TLR3 decreased in VAT depots of patients following gastric bypass $(-23 \%, \mathrm{p}<0.0001$, Table 1$)$. Given the changes identified in AT TLR expression upon weight loss and acute inflammation, we hypothesized that adipocyte-specific TLR could influence the local inflammatory milieu by promoting variations in their response. We used an in vitro model of differentiated human adipocytes treated with macrophage lipopolysaccharide (LPS)-conditioned media (MCM, $2 \%$ ), mimicking the conditions found in hyperplastic AT depots, including overexpression of proinflammatory cytokines and decreased adipocytes performance $[35,38]$. We measured the mRNA levels of TLR candidates in this model and in non-differentiated adipocyte precursor cells. Notably, TLR8 mRNA was detectable neither in adipocytes nor in preadipocytes, while the rest of TLR candidates showed decreased expression levels in mature lipid-containing adipocytes, when compared to non-differentiated precursor cells (Fig. 2). In partial agreement with changes observed upon acute surgical stress, MCM rescued to some extent decreased TLR2 in mature adipocytes, while further diminishing TLR3, TLR4, and TLR5 in differentiated (but not in non-differentiated) adipocytes (Table 1). Noteworthy, LPS raised the expression of both TLR2 and TLR3 in differentiated THP-1 macrophages (Table 1). Also of interest, TLR2 and TLR3 in activated macrophages and precursor fat cells were in parallel to 

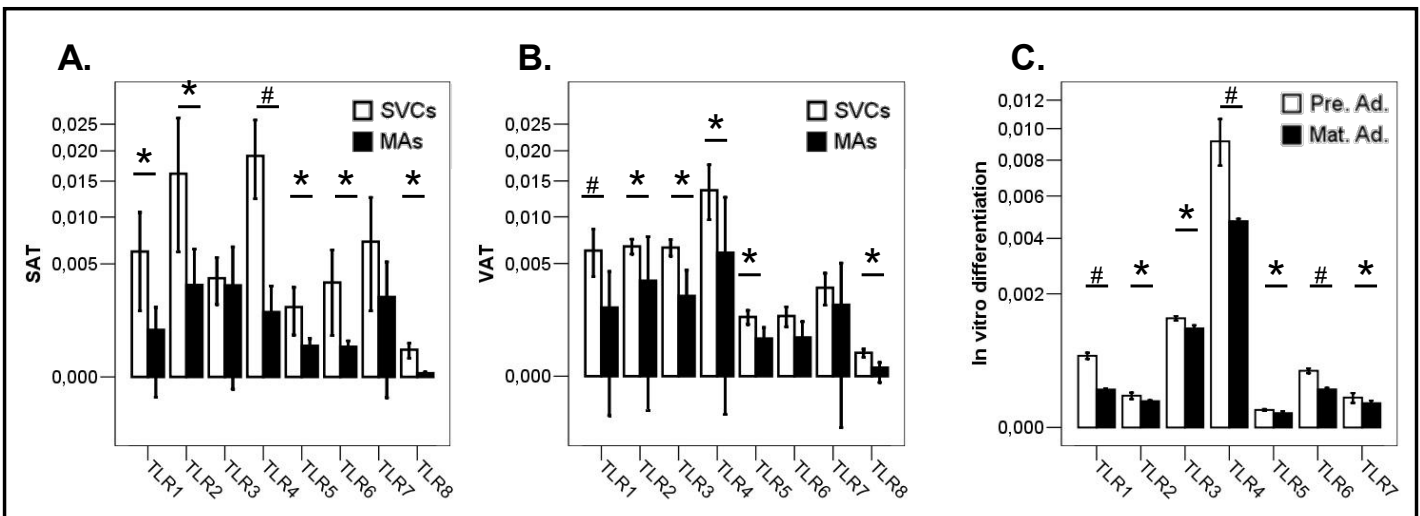

Fig. 2. Expression of toll-like receptors (TLR) in mature adipocytes (MAs) and stroma-vascular cells (SVCs) isolated from A. subcutaneous (SAT) and B. visceral (VAT) adipose tissue ( $\mathrm{n}=22$ paired samples). C. Expression of TLR in preadipocytes (Pre. Ad.) and mature adipocytes (Mat. Ad.) in vitro cultured and differentiated. The $y$-axis is the exponential of the relative gene expression. Error bars represent \pm 2 standard error. * stands for p-values $<0.05$, and ${ }^{\#}$ for p-values $<0.0001$.

the increased expression of proinflammatory cytokines such as tumor necrosis factor alpha $(\mathrm{TNF} \alpha)$ and interleukin 6 (IL-6), and in association with decreased insulin receptor substrate 1 (IRS1), glucose transporter 4 (GLUT4), and adiponectin (ADIPOQ) in mature adipocytes (Table 1). Finally, treatments aimed at endorsing the functional relevance of decreased TLR3 in differentiated adipocytes upon inflammation indicated that the response to the synthetic double-stranded RNA analog Poly(I:C) was significantly lower in MCM-activated cells (Fig. 3). Currently, decreased response to this specific agonist of TLR3 included not only changes affecting the inflammatory profile (i.e. lower expression of IL-6, TNF $\alpha$, or LBP) but also the lack (AQP9) or even the inversion (FASN, ELOVL6) of metabolic features in mature adipocytes responding to TLR3 agonist, including variations affecting lipolysis and lipogenesis (Fig. 3).
Table 1. Ratios assessed for gene expression measures obtained in subcutaneous (SAT) and visceral (VAT) adipose tissue after / before surgical procedures, THP-1 macrophages (M1) upon treatment with lipopolysaccharide (LPS), and in preadipocytes (PA) and mature adipocytes (MA) upon treatment with macrophages LPS-conditioned media (MCM). n.d. no detectable, n.a. not available

\begin{tabular}{|c|c|c|c|c|c|c|c|c|c|c|}
\hline & \multicolumn{4}{|c|}{ Effects of surgery } & \multirow{2}{*}{\multicolumn{6}{|c|}{$\begin{array}{c}\text { Impact of inflammation in vitro } \\
\text { MA + MCM }(2 \%) P A+\operatorname{MCM}(2 \%) M 1+\operatorname{LPS}(10 \mathrm{ng} / \mathrm{ml})\end{array}$}} \\
\hline & \multicolumn{2}{|c|}{ SAT } & \multicolumn{2}{|c|}{ VAT } & & & & & & \\
\hline & Ratio & p-value & Ratio & p-value & Ratio & $\mathrm{p}$-value & Ratio & p-value & Ratio & p-value \\
\hline \multicolumn{11}{|c|}{ Inflammation } \\
\hline IL-6 & 27.24 & $<0.0001$ & 27.28 & $<0.0001$ & 18.63 & $<0.0001$ & 31.06 & 0.001 & 17.74 & 0.002 \\
\hline $\mathrm{TNF} \alpha$ & 1.62 & 0.001 & 1.63 & 0.116 & 3.63 & $<0.0001$ & 11.19 & $<0.0001$ & 4.90 & 0.001 \\
\hline ADIPOQ & 0.84 & 0.343 & 0.92 & 0.793 & 0.34 & $<0.0001$ & n.d. & n.a. & n.d. & n.a. \\
\hline \multicolumn{11}{|c|}{ Glucose transport } \\
\hline IRS1 & 0.88 & 0.105 & 0.76 & 0.046 & 0.5 & $<0.0001$ & 0.99 & 0.955 & 0.45 & 0.004 \\
\hline GLUT4 & 0.81 & 0.134 & 0.77 & 0.191 & 0.22 & $<0.0001$ & n.d. & n.a. & 0.42 & 0.313 \\
\hline \multicolumn{11}{|c|}{ Toll-like receptors } \\
\hline TLR1 & 1.16 & 0.047 & 0.87 & 0.106 & 1.08 & 0.362 & 2.31 & 0.001 & 1.01 & 0.784 \\
\hline TLR2 & 1.58 & 0.044 & 2.07 & 0.003 & 3.67 & $<0.0001$ & 3.70 & $<0.0001$ & 1.46 & $<0.0001$ \\
\hline TLR3 & 1.04 & 0.5 & 0.77 & $<0.0001$ & 0.66 & 0.004 & 1.39 & 0.06 & 1.80 & 0.001 \\
\hline TLR4 & 1.23 & 0.002 & 1.11 & 0.529 & 0.53 & $<0.0001$ & 0.87 & 0.029 & 0.42 & $<0.0001$ \\
\hline TLR5 & 1.01 & 0.965 & 1.06 & 0.765 & 0.67 & 0.045 & 1.12 & 0.435 & 0.55 & 0.009 \\
\hline TLR6 & 1.01 & 0.982 & 1.02 & 0.93 & 0.98 & 0.816 & 1.01 & 0.967 & 0.60 & 0.004 \\
\hline TLR7 & 0.95 & 0.851 & 1.07 & 0.718 & 1.01 & 0.942 & 1.56 & 0.103 & 0.32 & $<0.0001$ \\
\hline TLR8 & 1.28 & 0.009 & 1.31 & 0.088 & n.d. & n.a. & n.d. & n.a. & 1.13 & 0.499 \\
\hline
\end{tabular}




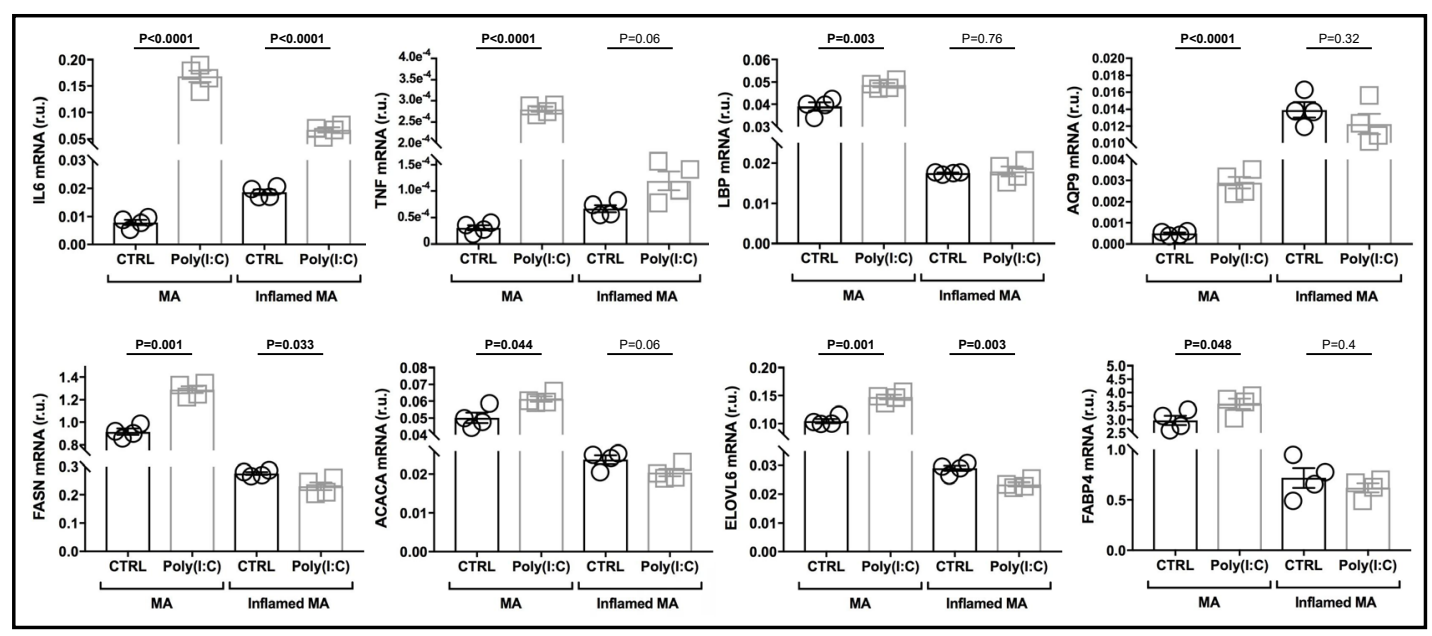

Fig. 3. The immunomodulatory potential and metabolic capacity of in vitro cultured and differentiated adipocytes responding to TLR3 agonists is blunted by inflammatory events (MCM) previous to treatment with Poly(I:C). Plots show expression variations of proinflammatory cytokines (IL-6: interleukin 6, TNF $\alpha$ : tumor necrosis factor alpha, LBP: lipopolysaccharide binding protein), and genes related to the lipolytic and lipogenic ability (AQP9: aquaporin 9, FASN: fatty acid synthase, ACACA: acetyl-CoA carboxylase-A, ELOVL6: fatty acid elongase 6, FABP4: fatty acid-binding protein 4) in human adipocytes under normal conditions (MA) and upon MCM (Inflamed MA). The y-axis is the relative gene expression (r.u.) for each gene.

\section{AT TLR expression patterns associate with clinical and inflammatory outputs}

We validated microarray results using real time PCR in an extended sample of 22 obese women in whom weight loss led to significantly decreased TLR1 $(-51 \%, \mathrm{p}<0.0001)$, TLR3 $(-18 \%, \mathrm{p}=0.01)$, and TLR8 $(-65 \%, \mathrm{p}<0.0001)$, running in parallel to dampened systemic inflammation (decreased blood leukocyte count and TNF $\alpha$ and IL-6 mRNA) and improved glucose and lipid metabolism, as shown by levels of fasting glucose, fasting triglycerides, HDL-cholesterol, and the expression of genes codifying for IRS1, GLUT4 and ADIPOQ (Table 2). As a further confirmation of these results, the expression of preselected TLR was quantified in SAT and VAT samples from 80 participants, including the obese patients included in our longitudinal study. Anthropometric, biochemical and gene expression results of participants are summarized in Table 3. The validation analysis shortlisted five TLR that differed significantly between morbid obese (BMI $\left.\geq 40 \mathrm{~kg} / \mathrm{m}^{2}\right)$ patients with or without type 2 diabetes (T2D), and sex and age-matched controls with BMI $<30 \mathrm{~kg} / \mathrm{m}^{2}$ and normal glucose tolerance (NGT). In agreement with longitudinal results, TLR1 (58\%, p=0.002, and 28\%, $\mathrm{p}=0.015)$ and TLR8 $(57 \%, \mathrm{p}=0.003$, and $32 \%, \mathrm{p}=0.026)$ were increased in SAT and VAT of obese individuals, respectively. In contrast, TLR3 show decreased expression in SAT (but not in VAT) of obese and diabetic participants, when compared to lean and obese subjects with NGT (Table 3). In this extended sample we also identified significant differences regarding SAT TLR5 and TLR6 (decreased in obese and T2D participants), and VAT TLR5, TLR7 (increased in obese subjects with NGT), and TLR6 (decreased in T2D patients when compared to sex, age, and weight-matched subjects). In partial agreement with previous data [3], we found a sustained increase of TLR1, TLR3, TLR5, and TLR7 in VAT, when compared to paired SAT samples from obese patients, but not in non-obese participants (Table 3). Accompanying group-related differences, SAT and VAT TLR1 $(p=0.013$ and $p=0.004)$, TLR5 $(p=0.025$ and $\mathrm{p}=0.046)$, TLR7 ( $\mathrm{p}=0.049$ and $\mathrm{p}=0.02)$, and TLR8 ( $\mathrm{p}=0.022$, only in SAT) were related to BMI (Table 4), and single correlations disclosed the positive association with pro-inflammatory genes such as TNF $\alpha$ (TLR1, TLR4, and TLR7) and IL-6 (TLR2, and TLR6) in SAT, and TLR1, TLR2, TLR6, and TLR8 in VAT (Table 4). Noteworthy, in both depots TLR4 was associated with ADIPOQ and TNF $\alpha$, pointing out its relationship with macrophages and the inflammatory/ metabolic state of differentiated adipocytes, while SAT TLR3 correlated with white blood 
cell (inversely) and lymphocyte counts (positively, Table 4). Regarding isolated AT cell fractions, stromal-vascular cells (SVC) were mainly responsible for TLR expressed in SAT and VAT, with minor differences between the TLR members analysed (Fig. 2). Noteworthy, the analysis of SVC sub-fractions indicated that the expression of TLR1 (2.4-fold, $\mathrm{p}=0.024$ ), TLR2 (3.8-fold, $\mathrm{p}<0.0001$ ), and TLR7 (3.9-fold change, $\mathrm{p}=0.002$ ) was increased in CD14+ cells, mostly composed of macrophages, while TLR3 mRNA was substantially lower in CD14+ cells $(-70 \%$, $\mathrm{p}=0.001)$ than in the rest of cells found in SVC fractions (data not shown). Among all TLR, the relatively low expression of TLR8 in both SVC and mature adipocytes from SAT and VAT depots was of particular interest. It should be also noted that all TLR results (but TLR3) ran in parallel to the expression levels of TNF $\alpha$ (27fold and 9-fold change in SAT and VAT, respectively) and the macrophage-specific expression of lysozyme (LYZ, also known as muramidase or $\mathrm{N}$-acetylmuramide glycanhydrolase, with 13-fold and 7-fold change in SVCs when compared to adipocytes from the same sample), while the mRNA of the adipocyte marker ADIPOQ was diminished in SVC, when compared to the depot-specific adipocyte fraction $(-98$ and $-99 \%$ in SAT and VAT, respectively, p-values $<0.0001$ for all comparisons, data not shown).

\section{TLR expression patterns in blood}

Previous studies have pointed at the use of blood cells (namely monocytes/macrophages, $\mathrm{B}$ and $\mathrm{T}$ lymphocytes, and natural killer cells) as a model to study inflammatory issues and systemic energy homeostasis disturbances [39-41]. Here, we sought analyze additional associations between TLR expressed in peripheral blood, which may be in line with previous observations in whole blood RNA as a marker for genomic changes in other tissues [42, 43]. In this independent sample of 72 participants, total leukocyte, neutrophil, and monocyte counts were increased in obese subjects, being total leukocytes count significantly associated with insulin resistance. Only TLR8 mRNA in blood cells was significantly associated with both BMI ( $\mathrm{r}=0.26, \mathrm{p}=0.028$ ) and metabolic impairment (Table 5), being this relationship mostly due to the link between increased neutrophil number and weight. Interestingly, expressions of almost all TLR (TLR4, TLR5, TLR6, and TLR8) were positively related to neutrophils but inversely associated with lymphocyte counts (TLR2, TLR4, and TLR6, Table 5). In blood samples, as well as in human AT, only TLR3 showed opposite patters with respect to the association with white blood cells, being positively linked to lymphocytes instead of neutrophils count (Table 5).

Table 2. Anthropometric, biochemical and gene expression data of 22 morbid obese women before (baseline) and $\sim 2$ years after (post-weight loss) bariatric surgery. Values represent the mean \pm standard pressure; DBP: diastolic blood pressure; HbA1C: glycated hemoglobin; HDL: high-density lipoprotein; LDL: low-density lipoprotein; WBC: white blood cells.

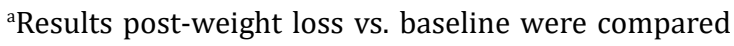
by paired t-test

\begin{tabular}{lccc}
\hline \multirow{2}{*}{ Parameters } & \multicolumn{3}{c}{ Longitudinal comparisons (n=22) } \\
& Baseline & Post-weight loss & p-valuea \\
\hline Age (yrs) & $49 \pm 8$ & $53 \pm 8$ & $<0.0001$ \\
BMI (kg / m2) & $43.2 \pm 5.2$ & $29.9 \pm 5.4$ & $<0.0001$ \\
Fat mass (\%) & $56.4 \pm 7.7$ & $41.2 \pm 7.1$ & $<0.0001$ \\
SBP (mmg) & $128.1 \pm 14.1$ & $131.1 \pm 16.7$ & 0.438 \\
DBP (mmg) & $79.0 \pm 10.1$ & $73.4 \pm 9.6$ & 0.03 \\
Glucose (mg / dl) & $95.3 \pm 14.4$ & $88.4 \pm 13.9$ & 0.022 \\
HbA1c (\%) & $5.5 \pm 0.6$ & $5.3 \pm 0.4$ & 0.38 \\
Cholesterol (mg / dl) & $184.5 \pm 34.8$ & $190.5 \pm 43.7$ & 0.404 \\
LDL (mg / dl) & $106.7 \pm 29.5$ & $103.5 \pm 30.1$ & 0.57 \\
HDL (mg / dl) & $55.8 \pm 13.3$ & $71.0 \pm 19.9$ & $<0.0001$ \\
Triglycerides (mg / dl) & $110.8 \pm 43.7$ & $80.0 \pm 27.8$ & 0.006 \\
WBC (KU / mcl) & $7.68 \pm 2.54$ & $5.57 \pm 1.56$ & $<0.0001$ \\
Neutrophils (KU / mcl) & $4.86 \pm 2.13$ & $3.19 \pm 1.29$ & $<0.0001$ \\
Lymphocytes (KU / mcl) & $2.02 \pm 0.61$ & $1.8 \pm 0.65$ & 0.005 \\
Monocytes (KU / mcl) & $0.53 \pm 0.22$ & $0.39 \pm 0.14$ & $<0.0001$ \\
IL-6 & $0.01695 \pm 0.06851$ & $0.0006 \pm 0.00034$ & 0.005 \\
TNFa & $0.00302 \pm 0.00205$ & $0.00074 \pm 0.00038$ & $<0.0001$ \\
ADIPOQ & $3.24 \pm 1.18$ & $4.57 \pm 1.61$ & 0.003 \\
IRS1 & $0.01070 \pm 0.00418$ & $0.01438 \pm 0.00602$ & 0.048 \\
GLUT4 & $0.04472 \pm 0.03356$ & $0.08758 \pm 0.05013$ & 0.006 \\
LEP & $0.9706 \pm 0.5073$ & $0.3327 \pm 0.2184$ & $<0.0001$ \\
TLR1 & $0.01177 \pm 0.00543$ & $0.00582 \pm 0.00150$ & $<0.0001$ \\
TLR2 & $0.00821 \pm 0.01292$ & $0.00575 \pm 0.00436$ & 0.399 \\
TLR3 & $0.01014 \pm 0.00273$ & $0.00828 \pm 0.00281$ & 0.01 \\
TLR4 & $0.02932 \pm 0.0213$ & $0.0196 \pm 0.01194$ & 0.056 \\
TLR5 & $0.00398 \pm 0.00572$ & $0.00269 \pm 0.00210$ & 0.325 \\
TLR6 & $0.00666 \pm 0.00769$ & $0.00482 \pm 0.00321$ & 0.292 \\
TLR7 & $0.00737 \pm 0.01322$ & $0.00466 \pm 0.00479$ & 0.361 \\
TLR8 & $0.00032 \pm 0.00013$ & $0.00011 \pm 0.00006$ & $<0.0001$ \\
\hline & & & \\
& & & \\
& & &
\end{tabular}




\section{Discussion}

Fighting against infection requires high energy turnover. Thereby, cells those are able to free energy to immunological utilization upon infection and tissue recovering need to be very sensitive to damage and pathogenassociated molecular patterns. In this context, emerging evidences immune and metabolic systems are highly integrated. Indeed, the increase of activated immune cells in obese subcutaneous (SAT) and visceral (VAT) adipose tissue is accompanied by important changes in adipocyte behavior $[38,44]$, modifying the differentiation state and expression and secretion of adipokines that, in turn, may regulate metabolism in AT and many other peripheral tissues [45]. Thus, innate immune pattern recognition receptors and tolllike receptors (TLR)endorse the notion that

Table 3. Anthropometric, biochemical and gene expression data of morbid obese (BMI $\left.\geq 40 \mathrm{~kg} / \mathrm{m}^{2}\right)$ patients with $(\mathrm{n}=30)$ or without $(\mathrm{n}=30)$ type 2 diabetes (T2D), and 20 controls with BMI $<30 \mathrm{~kg} / \mathrm{m}^{2}$ and normal glucose tolerance (NGT). Values represent the mean \pm standard deviation. ${ }^{a}$ One-way ANOVA; ${ }^{b}$ Student t-test for non-obese subjects vs. morbid obese patients with NGT; ${ }^{c}$ Student t-test for non-obese subjects with NGT vs. morbid obese patients with IR; ${ }^{d}$ Student $t$-test for obese volunteers with NGT vs. obese patients with IR. ${ }^{\dagger}$ For significant differences VAT vs. SAT in each group

\begin{tabular}{|c|c|c|c|c|c|c|c|}
\hline Parameter & Non-obese with NGT & Obese with NGT & Obese and $\mathrm{T} 2 \mathrm{D}$ & $\mathrm{p}$-value ${ }^{\mathrm{a}}$ & $\mathrm{p}$-value ${ }^{b}$ & $\mathrm{p}$-value ${ }^{c}$ & $p$-value \\
\hline $\mathrm{n}$ (men/women) & $8 / 12$ & $6 / 24$ & $8 / 22$ & & & & \\
\hline Age (years) & $47 \pm 13$ & $45 \pm 11$ & $49 \pm 13$ & 0.613 & 0.650 & 0.667 & 0.318 \\
\hline Body Mass Index $\left(\mathrm{kg} / \mathrm{m}^{2}\right)$ & $25.4 \pm 2.6$ & $47.2 \pm 8.3$ & $44.2 \pm 11.1$ & $<0.0001$ & $<0.0001$ & $<0.0001$ & 0.239 \\
\hline Fasting glucose $(\mathrm{mg} / \mathrm{dl})$ & $88.1 \pm 9.4$ & $95.6 \pm 9.8$ & $132.5 \pm 47.9$ & $<0.0001$ & 0.011 & $<0.0001$ & $<0.0001$ \\
\hline $\mathrm{Hb} 1 \mathrm{Ac}(\%)$ & $5.0 \pm 0.5$ & $5.0 \pm 0.5$ & $6.8 \pm 2.2$ & $<0.0001$ & 0.901 & 0.001 & 0.001 \\
\hline Cholesterol (mg / dl) & $194.7 \pm 37.6$ & $198.8 \pm 34.8$ & $195.4 \pm 36.5$ & 0.919 & 0.722 & 0.954 & 0.730 \\
\hline $\mathrm{HDL}(\mathrm{mg} / \mathrm{dl})$ & $58.7 \pm 17.6$ & $53.1 \pm 13.2$ & $51.5 \pm 12.4$ & 0.28 & 0.266 & 0.131 & 0.661 \\
\hline LDL (mg / dl) & $118.8 \pm 27.0$ & $117.4 \pm 28.2$ & $119.3 \pm 35.5$ & 0.977 & 0.881 & 0.963 & 0.839 \\
\hline Triglycerides (mg / dl) & $110.9 \pm 53.4$ & $126.0 \pm 82.0$ & $139.1 \pm 75.5$ & 0.495 & 0.527 & 0.209 & 0.548 \\
\hline $\mathrm{WBC}(\mathrm{KU} / \mathrm{mcl})$ & $6.58 \pm 1.97$ & $8 \pm 1.93$ & $8.57 \pm 2.73$ & 0.046 & 0.07 & 0.014 & 0.385 \\
\hline Neutrophils (KU / mcl) & $5 \pm 1.94$ & $6.95 \pm 10.1$ & $10.34 \pm 22.33$ & 0.56 & 0.71 & 0.314 & 0.437 \\
\hline Lymphocytes (KU / mcl) & $2.06 \pm 0.7$ & $2.6 \pm 1.01$ & $2.2 \pm 0.64$ & 0.113 & 0.064 & 0.62 & 0.106 \\
\hline Monocytes ( $\mathrm{KU} / \mathrm{mcl})$ & $0.7 \pm 0.33$ & $0.62 \pm 0.22$ & $0.51 \pm 0.14$ & 0.048 & 0.274 & 0.018 & 0.108 \\
\hline \multicolumn{8}{|c|}{ Gene expression measures in SAT } \\
\hline IL-6 in SAT & $0.03138 \pm 0.07049$ & $0.01879 \pm 0.03740$ & $0.00445 \pm 0.00904$ & 0.247 & 0.434 & 0.107 & 0.279 \\
\hline TNF $\alpha$ in SAT & $0.00528 \pm 0.00406$ & $0.00372 \pm 0.00210$ & $0.00325 \pm 0.00174$ & 0.152 & 0.14 & 0.06 & 0.624 \\
\hline ADIPOQ in SAT & $6.49 \pm 2.56$ & $4.58 \pm 2.43^{\dagger}$ & $3.22 \pm 2.04$ & 0.028 & 0.096 & 0.008 & 0.135 \\
\hline IRS1 in SAT & $0.01478 \pm 0.00902$ & $0.01183 \pm 0.00721$ & $0.00928 \pm 0.00514$ & 0.148 & 0.26 & 0.048 & 0.547 \\
\hline GLUT4 in SAT & $0.05794 \pm 0.02286$ & $0.04586 \pm 0.02833$ & $0.03490 \pm 0.01938^{\dagger}$ & 0.03 & 0.243 & 0.004 & 0.197 \\
\hline LEP in SAT & $0.62164 \pm 0.29487^{\dagger}$ & $0.71885 \pm 0.40399^{\dagger}$ & $0.80280 \pm 0.27587^{\dagger}$ & 0.241 & 0.485 & 0.074 & 0.547 \\
\hline TLR1 in SAT & $0.008233 \pm 0.003671$ & $0.010348 \pm 0.005216^{\dagger}$ & $0.012595 \pm 0.004669 \dagger$ & 0.025 & 0.189 & 0.005 & 0.119 \\
\hline TLR2 in SAT & $0.003261 \pm 0.002118$ & $0.003841 \pm 0.001945$ & $0.003407 \pm 0.002271$ & 0.659 & 0.387 & 0.844 & 0.485 \\
\hline TLR3 in SAT & $0.009118 \pm 0.002799$ & $0.008189 \pm 0.004020^{\dagger}$ & $0.00591 \pm 0.002862+$ & 0.008 & 0.414 & 0.001 & 0.027 \\
\hline TLR4 in SAT & $0.030824 \pm 0.011573$ & $0.027191 \pm 0.011112$ & $0.025591 \pm 0.009012$ & 0.221 & 0.169 & 0.092 & 0.525 \\
\hline TLR5 in SAT & $0.001369 \pm 0.000810$ & $0.001791 \pm 0.000815^{\dagger}$ & $0.001219 \pm 0.000631^{\dagger}$ & 0.038 & 0.120 & 0.523 & 0.012 \\
\hline TLR6 in SAT & $0.003456 \pm 0.002526$ & $0.003573 \pm 0.001679$ & $0.002467 \pm 0.001257$ & 0.087 & 0.860 & 0.114 & 0.014 \\
\hline TLR7 in SAT & $0.002469 \pm 0.001754$ & $0.002754 \pm 0.001476^{\dagger}$ & $0.002310 \pm 0.001313^{\dagger}$ & 0.591 & 0.582 & 0.748 & 0.282 \\
\hline TLR8 in SAT & $0.000250 \pm 0.000127$ & $0.000436 \pm 0.000367$ & $0.000330 \pm 0.000162$ & 0.067 & 0.026 & 0.098 & 0.195 \\
\hline \multicolumn{8}{|c|}{ Gene expression measures in VAT } \\
\hline IL-6 in VAT & $0.12775 \pm 0.32376$ & $0.00141 \pm 0.00337$ & $0.06117 \pm 0.15955$ & 0.205 & 0.152 & 0.946 & 0.134 \\
\hline TNF $\alpha$ in VAT & $0.00440 \pm 0.00364$ & $0.00883 \pm 0.01465$ & $0.00419 \pm 0.00324$ & 0.244 & 0.141 & 0.008 & 0.327 \\
\hline ADIPOQ in VAT & $8.36 \pm 5.42$ & $2.75 \pm 1.63$ & $2.13 \pm 2.69$ & 0.002 & 0.002 & 0.001 & 0.647 \\
\hline IRS1 in VAT & $0.01615 \pm 0.01035$ & $0.01029 \pm 0.00550$ & $0.00877 \pm 0.00396$ & 0.018 & 0.023 & 0.008 & 0.546 \\
\hline GLUT4 in VAT & $0.05112 \pm 0.03086$ & $0.03493 \pm 0.03598$ & $0.02458 \pm 0.01936$ & 0,029 & 0.212 & 0.006 & 0.306 \\
\hline LEP in VAT & $0.17322 \pm 0.13117$ & $0.24999 \pm 0.14024$ & $0.36453 \pm 0.17723$ & 0.005 & 0.213 & 0.001 & 0.063 \\
\hline TLR1 in VAT & $0.009884 \pm 0.004478$ & $0.017714 \pm 0.011738$ & $0.016905 \pm 0.007650$ & 0.019 & 0.003 & 0.001 & 0.771 \\
\hline TLR2 in VAT & $0.003494 \pm 0.002344$ & $0.006529 \pm 0.007623$ & $0.003922 \pm 0.003388$ & 0.121 & 0.064 & 0.668 & 0.114 \\
\hline TLR3 in VAT & $0.009073 \pm 0.002927$ & $0.009517 \pm 0.003832$ & $0.008860 \pm 0.004032$ & 0.806 & 0.690 & 0.855 & 0.542 \\
\hline TLR4 in VAT & $0.033063 \pm 0.011468$ & $0.032169 \pm 0.011247$ & $0.032646 \pm 0.009237$ & 0.937 & 0.724 & 0.887 & 0.856 \\
\hline TLR5 in VAT & $0.001421 \pm 0.000796$ & $0.002612 \pm 0.001471$ & $0.001956 \pm 0.001158$ & 0.01 & 0.001 & 0.112 & 0.078 \\
\hline TLR6 in VAT & $0.003051 \pm 0.001971$ & $0.004658 \pm 0.003378$ & $0.002935 \pm 0.001221$ & 0.025 & 0.091 & 0.833 & 0.018 \\
\hline TLR7 in VAT & $0.002383 \pm 0.001537$ & $0.003504 \pm 0.001943$ & $0.003202 \pm 0.002067$ & 0.180 & 0.043 & 0.179 & 0.586 \\
\hline TLR8 in VAT & $0.000248 \pm 0.000113$ & $0.000503 \pm 0.000637$ & $0.000344 \pm 0.000161$ & 0.156 & 0.049 & 0.036 & 0.210 \\
\hline
\end{tabular}

mediated signaling pathways act as direct sensors for cellular activation, leading to important changes in glucose and lipid homeostasis [46]. Humans possess 10 toll-like receptor (TLR) family members. TLR1, 2, 4, 5, and 6 traffic to the plasma membrane, sense microbial cell components and pathogen-associated molecular patterns, and stimulate the production of proinflammatory molecules. TLRs 3, 7, 8, and 9 are located in endosomal compartments, intercept viral and bacterial nucleic acids, and are best known for their ability to stimulate the production of type 1 interferons [47]. The present study shows concomitant changes affecting the expression levels of TLR found in obese AT and being modified upon surgeryinduced inflammation and weight loss. Current observations point out the activated state of adipocytes and infiltrating immune cells found in AT, being intimately associated with the degree of obesity, inflammation, and metabolic impairment. 
Latorre et al.: TLR3 and Metabolic Inflammation

Table 4. Partial correlations (Pearson) between expression of toll-like receptors (TLR) in subcutaneous (upper panel) and visceral (lower panel) adipose tissue and studied variables

\begin{tabular}{|c|c|c|c|c|c|c|c|c|c|c|c|c|c|c|c|c|}
\hline \multirow{3}{*}{ Parameter } & \multicolumn{16}{|c|}{ Subcutaneous adipose tissue (SAT) } \\
\hline & \multicolumn{2}{|c|}{ TLR1 } & \multicolumn{2}{|c|}{ TLR2 } & \multicolumn{2}{|c|}{ TLR3 } & \multicolumn{2}{|c|}{ TLR4 } & \multicolumn{2}{|c|}{ TLR5 } & \multicolumn{2}{|c|}{ TLR6 } & \multicolumn{2}{|c|}{ TLR7 } & \multicolumn{2}{|c|}{ TLR8 } \\
\hline & $\mathrm{r}$ & $\mathrm{p}$ & $\mathrm{r}$ & $\mathrm{p}$ & $\mathrm{r}$ & $\mathrm{p}$ & $\mathrm{r}$ & $\mathrm{p}$ & $\mathrm{r}$ & $\mathrm{p}$ & $\mathrm{r}$ & $\mathrm{p}$ & $\mathrm{r}$ & $\mathrm{p}$ & $\mathrm{r}$ & $\mathrm{p}$ \\
\hline ge (years) & -0.12 & 0.34 & 0.197 & 0.119 & 0.017 & 0.893 & -0.102 & .266 & 0.181 & 0.156 & -0.151 & 0.229 & 0.153 & 0.224 & 0.066 & 0.592 \\
\hline $\mathrm{m}^{2}$ ) & 0.306 & 0.013 & 0.07 & 0.581 & -0.163 & 0.184 & -0.028 & 0.764 & 0.284 & 0.025 & -0.035 & 0.78 & 247 & 0.049 & 0.277 & .022 \\
\hline / dl) & 0.259 & 0.04 & 0.081 & 0.529 & -0.239 & 0.053 & -0.032 & 0.728 & 0.05 & 0.7 & -0.05 & 0.693 & 092 & 0.47 & 133 & 0.286 \\
\hline b1A & 219 & 0.118 & 0.141 & 0.317 & -0.056 & 0.689 & -0.212 & 0.052 & -0.043 & 0.763 & -0.034 & & 048 & & 0.17 & 0.22 \\
\hline $\mathrm{l}(\mathrm{mg} / \mathrm{dl})$ & 0.062 & 0.644 & 0.145 & 0.279 & 0.189 & 0.146 & -0.024 & 0.798 & & 0.929 & 0.094 & & .086 & & 0.204 & 0.115 \\
\hline & -0.008 & 0.957 & -0.016 & 0.912 & & 0.012 & -0.2 & & & 0.282 & & & & & & 0.957 \\
\hline & & & & & & & & & & & & & & & & 0.579 \\
\hline & & & & & & & & & & & & & & & & 884 \\
\hline & & 0.2 & & & & & & & & & & & & & & 263 \\
\hline & -0.0 & & & & & 289 & & & & & & & & & & 0.386 \\
\hline & 0.034 & 0.806 & 041 & 0.768 & 193 & 151 & 0.073 & & -0.067 & 0.633 & 0.021 & 0.881 & .047 & 0.732 & 0.184 & 0.17 \\
\hline & 151 & 0.258 & 115 & 0.388 & -0.057 & 0.664 & -0.018 & 0.846 & -0.06 & 0.663 & 0.02 & 0.882 & 0.037 & 0.786 & .223 & 0.086 \\
\hline & 073 & 0.667 & 0.704 & $<0.001$ & 0.001 & 0.993 & 0.123 & 0.285 & .271 & 0.11 & 0.66 & $<0.001$ & 0.211 & 0.203 & .087 & 0.595 \\
\hline & & 0.03 & 0.126 & 0.469 & 0.277 & 0.097 & 0.323 & 0.001 & 147 & 0.406 & 0.16 & 0.352 & 0.554 & $<0.001$ & 0.203 & 0.227 \\
\hline ADIPO & -0.401 & 0.035 & 0.071 & 0.725 & 0.331 & 0.079 & 0.3 & 0.016 & -0.007 & 0.973 & 0.139 & 0.488 & -0.187 & 0.35 & 0.058 & 0.764 \\
\hline & -0.222 & 0.174 & -0.204 & 0.206 & -0.06 & 0.71 & 0.151 & 0.131 & -0.046 & 0.782 & -0.096 & 0.552 & -0.143 & 0.371 & -0.172 & 0.281 \\
\hline GLUT4 in SA & -0.113 & 0.488 & -0.022 & 0.895 & 0.105 & 0.509 & & 0.935 & -0.142 & 0.388 & -0.056 & 0.733 & -0.132 & 0.415 & -0.144 & 0.364 \\
\hline LEP in SAT & 0.085 & 0.644 & -0.03 & 0.869 & -0.46 & 0.005 & -0.201 & 0.082 & -0.202 & 0.253 & -0.091 & 0.611 & -0.085 & 0.633 & 0.005 & 0.979 \\
\hline
\end{tabular}

Age (years)

BMI $\left(\mathrm{kg} / \mathrm{m}^{2}\right)$

Glucose (mg / dl)

Hb1Ac (\%)

Cholesterol (mg / dl)

HDL (mg / dl)

LDL (mg / dl)

Triglycerides (mg / dl)

WBC (KU / mcl)

Neutrophils $(\mathrm{KU} / \mathrm{mcl})$

Lymphocytes $(\mathrm{KU} / \mathrm{mcl})$
Monocytes $(\mathrm{KU} / \mathrm{mcl})$

IL-6 in VAT

TNF $\alpha$ in VAT

ADIPOQ in VAT

IRS1 in VAT

GLUT4 in VAT

LEP in VAT

\begin{tabular}{|c|c|c|c|c|c|c|c|c|c|c|c|c|c|c|c|}
\hline & & & & & & & & & & & & & & & \\
\hline & $\mathrm{R} 1$ & & R2 & TL & & & R4 & & & & & & & & R8 \\
\hline $\mathrm{r}$ & $\mathrm{p}$ & $\mathrm{r}$ & $\mathrm{p}$ & $\mathrm{r}$ & $\mathrm{p}$ & $\mathrm{r}$ & $\mathrm{p}$ & $\mathrm{r}$ & $\mathrm{p}$ & $\mathrm{r}$ & $\mathrm{p}$ & $r$ & $\mathrm{p}$ & $r$ & $\mathrm{p}$ \\
\hline 0.193 & 0.107 & -0.119 & 0.326 & -0.022 & 0.854 & 0.01 & 0.911 & 0.053 & 0.661 & 0.192 & 0.109 & 0.016 & 0.897 & -0.218 & 0.07 \\
\hline 0.334 & 0.004 & 0.194 & 0.108 & 0.029 & 0.806 & -0.016 & 0.863 & 0.237 & 0.046 & 0.066 & 0.586 & 0.276 & 0.02 & 0.185 & 0.126 \\
\hline 0.094 & 0.44 & -0.054 & 0.663 & -0.094 & 0.437 & 0.052 & 0.585 & 0.028 & 0.818 & -0.093 & 0.448 & 0.009 & 0.941 & -0.037 & 0.765 \\
\hline-0.064 & 0.648 & -0.143 & 0.308 & -0.047 & 0.733 & 0.032 & 0.773 & -0.055 & 0.693 & -0.135 & 0.33 & -0.102 & 0.463 & -0.152 & .278 \\
\hline 0.224 & 0.075 & 0.213 & 0.093 & 0.266 & 0.032 & -0.025 & 0.799 & 0.183 & 0.148 & 0.352 & & 0.309 & 0.013 & 0.166 & 0.194 \\
\hline-0.047 & 0.721 & 0.027 & 0.837 & 0.091 & 0.482 & -0.038 & 0.7 & 0.145 & 0.265 & 0.241 & & 0.23 & 0.075 & -0.055 & 0.674 \\
\hline 0.164 & 0.215 & -0.005 & 0.972 & 0.274 & 0.034 & 0.062 & 0.551 & 0.034 & 0.798 & 0.11 & 0.409 & 0.177 & 0.179 & 0.023 & 0.863 \\
\hline 0.081 & 0.528 & 0.052 & 0.686 & 0.116 & 0.361 & 0.078 & 0.428 & 0.096 & 0.456 & 0.116 & 0.364 & 0.074 & 0.562 & 0.045 & 0.727 \\
\hline-0.118 & 0.382 & -0.067 & 0.624 & -0.304 & 0.027 & -0.099 & 0.465 & -0.056 & 0.68 & -0.203 & 0.129 & -0.109 & 0.422 & -0.118 & 0.382 \\
\hline 0.039 & 0.774 & -0.032 & 0.814 & -0.211 & 0.133 & 0.025 & 0.851 & 0.02 & 0.88 & -0.052 & 0.699 & -0.038 & 0.779 & 0.039 & 0.774 \\
\hline-0.152 & 0.258 & 0.016 & 0.909 & 0.356 & 0.01 & 0.312 & 0.018 & 0.433 & 0.001 & 0.15 & 0.267 & -0.144 & 0.288 & -0.152 & 0.258 \\
\hline-0.182 & 0.175 & 0.072 & 0.596 & 0.122 & 0.387 & -0.021 & 0.877 & 0.141 & 0.295 & -0.038 & 0.779 & 0.026 & 0.85 & -0.182 & 0.175 \\
\hline-0.088 & 0.559 & 0.44 & 0.003 & 0.066 & 0.663 & 0.110 & 0.4 & -0.012 & 0.937 & 0.098 & 0.52 & 0.052 & 0.736 & 0.056 & 0.713 \\
\hline 0.609 & $<0.001$ & 0.572 & $<0.001$ & 0.012 & 0.935 & 0.417 & $<0.001$ & 0.001 & 0.993 & 0.302 & 0.037 & 0.156 & 0.29 & 0.657 & $<0.001$ \\
\hline-0.331 & 0.092 & -0.058 & 0.778 & 0.291 & 0.141 & 0.377 & 0.048 & -0.084 & 0.683 & 0.035 & 867 & -0.177 & 0.387 & -0.063 & 0.755 \\
\hline-0.401 & 0.008 & 261 & 0.087 & .225 & 0.141 & 025 & 122 & -0.051 & 0.744 & -0.067 & 0.665 & -0.199 & 0.196 & -0.339 & 0.026 \\
\hline .206 & 0.174 & -0.099 & 0.519 & -0.14 & 0.357 & -0.028 & 0.837 & -0.219 & 0.147 & -0.169 & 0.268 & -0.254 & 0.092 & -0.004 & 0.98 \\
\hline 0.11 & 0.498 & -0.131 & 0.42 & -0.021 & 0.897 & 0.13 & 0.364 & 0.041 & 0.802 & -0.132 & 0.417 & -0.056 & 0.731 & -0.097 & 0.551 \\
\hline
\end{tabular}

Table 5. Partial correlation (Spearman) between expression of toll-like receptors (TLR) in whole and studied variables in an independent cross-sectional sample $(n=72)$

\begin{tabular}{|c|c|c|c|c|c|c|c|c|c|c|c|c|c|c|c|c|}
\hline \multirow{3}{*}{ Parameter } & \multicolumn{16}{|c|}{ Whole blood gene expression } \\
\hline & \multicolumn{2}{|c|}{ TLR1 } & \multicolumn{2}{|c|}{ TLR2 } & \multicolumn{2}{|c|}{ TLR3 } & \multicolumn{2}{|c|}{ TLR4 } & \multicolumn{2}{|c|}{ TLR5 } & \multicolumn{2}{|c|}{ TLR6 } & \multicolumn{2}{|c|}{ TLR7 } & \multicolumn{2}{|c|}{ TLR8 } \\
\hline & $\mathrm{r}$ & $\mathrm{p}$ & $\mathrm{r}$ & $\mathrm{p}$ & $r$ & $\mathrm{p}$ & $\mathrm{r}$ & $\mathrm{p}$ & $\mathrm{r}$ & $\mathrm{p}$ & $\mathrm{r}$ & $\mathrm{p}$ & $\mathrm{r}$ & $\mathrm{p}$ & $\mathrm{r}$ & $\mathrm{p}$ \\
\hline Age (years) & -0.06 & 0.614 & 0.102 & 0.399 & -0.053 & 0.671 & 0.199 & 0.08 & -0.010 & 0.936 & 0.174 & 0.143 & -0.017 & 0.888 & 0.077 & 0.52 \\
\hline BMI $\left(\mathrm{kg} / \mathrm{m}^{2}\right)$ & 0.13 & 0.275 & -0.092 & 0.447 & 0.011 & 0.93 & 0.134 & 0.242 & 0.114 & 0.339 & 0.102 & 0.396 & -0.081 & 0.503 & 0.257 & 0.028 \\
\hline Glucose (mg / dl) & 0.055 & 0.645 & -0.006 & 0.964 & 0.153 & 0.219 & 0.036 & 0.752 & -0.087 & 0.47 & 0.002 & 0.988 & -0.083 & 0.491 & 0.078 & 0.51 \\
\hline $\mathrm{Hb} 1 \mathrm{Ac}(\%)$ & 0.025 & 0.834 & -0.168 & 0.166 & 0.128 & 0.305 & -0.011 & 0.926 & -0.187 & 0.116 & -0.050 & 0.678 & -0.158 & 0.187 & 0.012 & 0.923 \\
\hline Cholesterol (mg / dl) & 0.248 & 0.037 & 0.175 & 0.15 & -0.055 & 0.664 & -0.021 & 0.855 & 0.204 & 0.088 & 0.220 & 0.066 & 0.146 & 0.228 & 0.131 & 0.272 \\
\hline HDL (mg / dl) & -0.133 & 0.264 & 0.056 & 0.646 & 0.032 & 0.799 & -0.018 & 0.877 & -0.166 & 0.165 & -0.004 & 0.975 & 0.100 & 0.406 & -0.355 & 0.002 \\
\hline LDL (mg / dl) & 0.202 & 0.093 & 0.155 & 0.207 & -0.050 & 0.694 & -0.023 & 0.844 & 0.258 & 0.031 & 0.181 & 0.133 & 0.057 & 0.644 & 0.192 & 0.109 \\
\hline Triglycerides (mg / dl) & 0.166 & 0.162 & -0.094 & 0.44 & -0.156 & 0.211 & 0.024 & 0.833 & 0.011 & 0.924 & -0.037 & 0.755 & -0.085 & 0.481 & 0.3 & 0.01 \\
\hline $\mathrm{WBC}(\mathrm{KU} / \mathrm{mcl})$ & 0.127 & 0.288 & -0.027 & 0.823 & -0.084 & 0.503 & 0.100 & 0.382 & 0.243 & 0.040 & 0.115 & 0.338 & -0.092 & 0.446 & 0.406 & $<0.001$ \\
\hline Neutrophils (KU / mcl) & 0.17 & 0.155 & 0.197 & 0.104 & -0.227 & 0.069 & 0.292 & 0.01 & 0.393 & 0.001 & 0.309 & 0.009 & -0.051 & 0.672 & 0.487 & $<0.001$ \\
\hline Lymphocytes (KU / mcl) & -0.097 & 0.418 & -0.477 & $<0.001$ & 0.308 & 0.003 & -0.270 & 0.017 & -0.217 & 0.067 & -0.327 & 0.005 & -0.140 & 0.246 & -0.025 & 0.831 \\
\hline Monocytes (KU / mcl) & 0.015 & 0.898 & -0.022 & 0.858 & 0.015 & 0.906 & -0.119 & 0.298 & 0.170 & 0.153 & -0.060 & 0.617 & -0.066 & 0.583 & 0.250 & 0.033 \\
\hline $\mathrm{TNF} \alpha$ in WB & -0.214 & 0.071 & 0.171 & 0.157 & -0.156 & 0.212 & 0.599 & $<0.001$ & -0.020 & 0.867 & 0.041 & 0.734 & 0.089 & 0.459 & -0.009 & 0.938 \\
\hline LEP in WB & 0.211 & 0.092 & 0.336 & 0.007 & -0.179 & 0.167 & 0.387 & 0.001 & 0.388 & 0.001 & 0.335 & 0.006 & 0.155 & 0.217 & 0.152 & 0.219 \\
\hline
\end{tabular}

\section{Stress-induced inflammation promotes the shift of TLR expressed by adipocytes}

Inflammation caused by the presence and activation of infiltrating immune cells is preceded by white blood cells relocation $[48,49]$, paving the way for the recruitment of macrophages and the inflammatory state of activation of mature adipocytes [50]. Here, we found decreased TLR3 gene expression levels accompanying increased TLR2 in obese/ inflamed mature adipocytes. The opposite expression pattern identified for TLR3 and TLR2 was endorsed by i) decreased TLR3 but increased TLR2 gene expression in VAT during acute surgical inflammation, ii) the negative response of TLR3 to the macrophage-conditioned 


\begin{tabular}{|c|c|c|c|c|c|c|c|c|c|c|c|c|}
\hline & \multicolumn{10}{|c|}{ In vivo (human adipose tissue) } & \multicolumn{2}{|c|}{ In vitro (human adipocytes) } \\
\hline & \multirow{2}{*}{\begin{tabular}{|l} 
Post-weight \\
loss \\
SAT \\
(microarray)
\end{tabular}} & \multirow{2}{*}{$\begin{array}{l}\text { Post-weight } \\
\text { loss } \\
\text { SAT } \\
\text { (RT-PCR) }\end{array}$} & \multicolumn{2}{|c|}{ Obesity } & \multicolumn{2}{|c|}{ Obesity + T2D } & \multicolumn{2}{|c|}{$\begin{array}{l}\text { Association with } \\
\text { inflammation }\end{array}$} & \multicolumn{2}{|c|}{ During surgery } & \multirow{2}{*}{\begin{tabular}{|l} 
SGBS \\
+ MCM (14\%)
\end{tabular}} & \multirow{2}{*}{$\begin{array}{l}\text { Primary } \\
\text { adipocytes } \\
+ \text { MCM }(2.5 \%)\end{array}$} \\
\hline & & & SAT & VAT & SAT & VAT & SAT & VAT & SAT & VAT & & \\
\hline TLR1 & $\downarrow \downarrow$ & $\downarrow \downarrow \downarrow$ & $\uparrow \sim$ & $\uparrow \uparrow$ & $\uparrow$ & $\uparrow \uparrow$ & $\uparrow$ & $\uparrow \uparrow$ & $\uparrow$ & $\sim$ & $\downarrow$ & $\tilde{\mu}$ \\
\hline TLR2 & $\downarrow \downarrow$ & $\sim$ & $\sim$ & $\sim$ & 〜 & $\sim$ & $\sim$ & $\uparrow \uparrow$ & $\uparrow$ & $\uparrow \uparrow$ & $\uparrow \uparrow \uparrow$ & $\uparrow \uparrow \uparrow$ \\
\hline TLR3 & $\downarrow$ & $\downarrow$ & $\downarrow \sim$ & $\sim$ & $\downarrow \downarrow$ & $\sim$ & $\sim$ & $\sim$ & $\sim$ & $\downarrow \downarrow$ & $\downarrow \downarrow \downarrow$ & $\downarrow \downarrow$ \\
\hline TLR4 & $\downarrow \sim$ & $\downarrow \sim$ & $\sim$ & $\sim$ & $\sim$ & $\sim$ & $\uparrow \sim$ & $\uparrow \sim$ & $\uparrow$ & $\sim$ & $\downarrow \sim$ & $\downarrow \downarrow \downarrow$ \\
\hline TLR5 & $\downarrow \downarrow$ & $\sim$ & $\uparrow \sim$ & $\uparrow$ & $\downarrow \sim$ & $\uparrow \sim$ & $\sim$ & $\sim$ & $\sim$ & $\sim$ & $\sim$ & $\sim$ \\
\hline TLR6 & $\downarrow \downarrow$ & $\sim$ & $\sim$ & $\uparrow \sim$ & $\downarrow \sim$ & $\downarrow \sim$ & $\sim$ & $\uparrow$ & $\sim$ & $\sim$ & $\sim$ & $\sim$ \\
\hline TLR7 & $\downarrow \downarrow$ & $\sim$ & $\sim$ & $\uparrow$ & $\sim$ & $\uparrow \sim$ & $\uparrow \uparrow$ & $\sim$ & $\sim$ & $\sim$ & $\uparrow$ & $\sim$ \\
\hline TLR8 & $\downarrow \downarrow \downarrow$ & $\downarrow \downarrow \downarrow$ & $\uparrow$ & $\uparrow$ & $\uparrow \sim$ & $\uparrow \sim$ & $\sim$ & $\uparrow \uparrow$ & $\uparrow$ & $\uparrow \sim$ & $\sim$ & n.d. \\
\hline
\end{tabular}

Fig. 4. Integrated summary of results observed in vivo (subcutaneous (SAT) and visceral (VAT) adipose tissue) and in vitro (human differentiated adipocytes). One, two, or three arrows identify the degree of change affecting significant variations in single comparisons. $\uparrow \sim$ for nominal non-significant differences (0.1> p-value $>0.05)$, and $\sim$ when the same expression levels were shown. n.d. means no detectable.

Table 6. Single associations for Spearman between toll-like receptor 2 (TLR2) and 3 (TLR3) and other genes expressed in adipose tissue at the baseline (PRE) and $\sim 2$ years after bariatric surgery (POST)

\begin{tabular}{|c|c|c|c|c|c|c|c|c|c|}
\hline Symbol & $\mathrm{r}-\mathrm{PRE}$ & p-PRE & lower-PRE & Upper-PRE & r-POST & p-POST & lower-POST & Upper-POST & Definition \\
\hline \multicolumn{10}{|l|}{ TLR2 } \\
\hline SNX10 & 0.629 & 0.0089881 & 0.194 & 0.858 & 0.726 & 0.0014362 & 0.361 & 0.899 & sorting nexin 10 \\
\hline COPA & 0.729 & 0.0013431 & 0.366 & 0.9 & 0.685 & 0.0033916 & 0.287 & 0.882 & coatomer protein complex. subunit alpha \\
\hline SLC11A2 & 0.671 & 0.0044672 & 0.262 & 0.875 & 0.671 & 0.0044672 & 0.262 & 0.875 & solute carrier family 11 member 2 \\
\hline ATXN2 & -0.644 & 0.0070815 & -0.864 & -0.218 & 0.659 & 0.0055114 & 0.242 & 0.87 & ataxin 2 \\
\hline MACC1 & 0.662 & 0.0052338 & 0.247 & 0.872 & -0.626 & 0.009414 & -0.856 & -0.19 & metastasis associated in colon cancer 1 \\
\hline ST13 & -0.753 & 0.0007611 & -0.909 & -0.41 & -0.632 & 0.0085776 & -0.859 & -0.199 & suppression of tumorigenicity 13 (colon carcinoma) \\
\hline FAM65B & 0.741 & 0.0010185 & 0.388 & 0.905 & -0.65 & 0.0064157 & -0.867 & -0.228 & family with sequence similarity 65 . member B \\
\hline CLEC4E & 0.753 & 0.0007611 & 0.41 & 0.909 & -0.653 & 0.006102 & -0.868 & -0.232 & C-type lectin domain family 4. member E \\
\hline RN5S22 & -0.756 & 0.0007059 & -0.91 & -0.416 & -0.688 & 0.0032039 & -0.883 & -0.292 & RNA. 5 S ribosomal 22 \\
\hline CDH19 & -0.635 & 0.0081821 & -0.86 & -0.204 & -0.779 & 0.0003717 & -0.92 & -0.462 & cadherin 19. type 2 \\
\hline \multicolumn{10}{|l|}{ TLR3 } \\
\hline UPK3BL & 0.732 & 0.001255 & 0.372 & 0.901 & 0.809 & 0.0001485 & 0.523 & 0.931 & uroplakin 3B-like \\
\hline POLR2J4 & 0.871 & 0.0000115 & 0.659 & 0.954 & 0.753 & 0.0007611 & 0.41 & 0.909 & polymerase (RNA) II (DNA directed) polypeptide J4 \\
\hline POLR2J2 & 0.653 & 0.006102 & 0.232 & 0.868 & 0.706 & 0.0022459 & 0.323 & 0.89 & polymerase (RNA) II (DNA directed) polypeptide J2 \\
\hline GCOM1 & 0.644 & 0.0070815 & 0.218 & 0.864 & 0.697 & 0.0026906 & 0.308 & 0.886 & GRINL1A complex locus 1 \\
\hline LEPR & 0.776 & 0.0004044 & 0.456 & 0.919 & 0.691 & 0.0030247 & 0.297 & 0.884 & leptin receptor \\
\hline ZMYM4 & 0.641 & 0.0074344 & 0.213 & 0.863 & 0.679 & 0.0037934 & 0.277 & 0.879 & zinc finger. MYM-type 4 \\
\hline HLTF & 0.697 & 0.0026906 & 0.308 & 0.886 & 0.674 & 0.0042327 & 0.267 & 0.877 & helicase-like transcription factor \\
\hline TRMT1L & 0.691 & 0.0030247 & 0.297 & 0.884 & 0.674 & 0.0042327 & 0.267 & 0.877 & tRNA methyltransferase 1 homolog ( $\mathrm{S}$. cerevisiae)-like \\
\hline TRAJ2 & 0.685 & 0.0033916 & 0.287 & 0.882 & 0.674 & 0.0042327 & 0.267 & 0.877 & $\mathrm{~T}$ cell receptor alpha joining 2 (non-functional) \\
\hline SNAPC3 & 0.65 & 0.0064157 & 0.228 & 0.867 & 0.671 & 0.0044672 & 0.262 & 0.875 & small nuclear RNA activating complex. polypeptide 3 \\
\hline USO1 & 0.797 & 0.0002181 & 0.498 & 0.927 & 0.662 & 0.0052338 & 0.247 & 0.872 & US01 vesicle docking protein homolog (yeast) \\
\hline MAN1A2 & 0.735 & 0.0011716 & 0.377 & 0.902 & 0.641 & 0.0074344 & 0.213 & 0.863 & mannosidase. alpha. class $1 \mathrm{~A}$. member 2 \\
\hline COG6 & 0.747 & 0.0008821 & 0.399 & 0.907 & 0.635 & 0.0081821 & 0.204 & 0.86 & component of oligomeric golgi complex 6 \\
\hline TMX1 & 0.785 & 0.0003129 & 0.474 & 0.922 & 0.632 & 0.0085776 & 0.199 & 0.859 & thioredoxin-related transmembrane protein 1 \\
\hline NDNL2 & 0.668 & 0.004712 & 0.257 & 0.874 & 0.626 & 0.009414 & 0.19 & 0.856 & necdin-like 2 \\
\hline ITGB1BP1 & 0.632 & 0.0085776 & 0.199 & 0.859 & 0.624 & 0.0098557 & 0.185 & 0.855 & integrin beta 1 binding protein 1 \\
\hline CENPT & -0.7 & 0.0025351 & -0.888 & -0.313 & -0.624 & 0.0098557 & -0.855 & -0.185 & centromere protein $\mathrm{T}$ \\
\hline TRAV8-1 & -0.662 & 0.0052338 & -0.872 & -0.247 & -0.7 & 0.0025351 & -0.888 & -0.313 & $\mathrm{~T}$ cell receptor alpha variable $8-1$ \\
\hline METTL17 & -0.656 & 0.0058007 & -0.869 & -0.237 & -0.709 & 0.0021117 & -0.891 & -0.329 & methyltransferase like 17 \\
\hline
\end{tabular}

milieu, and the positive impact on TLR2 mRNA in human adipocytes and differentiated SGBS cells (Fig. 1B, according to the microarray results of reference [51]), iii) the decreased expression levels found for SAT TLR3 in obese individuals with and without type 2 diabetes (T2D), as compared with lean counterparts with normal glucose tolerance, and iv) the positive association of TLR2 with inflammation and decreased glucose tolerance (Fig. 4). Current results validate the synergistic impact of obesity-related inflammation and decreased glucose intake on TLR2, being positively associated with physiological variations such as leukocyte/ neutrophil numbers, inflammatory activation of fat cells, and fasting glycemia following weight loss $[52,53]$, while TLR3 in mature adipocytes responded negatively to the inflammatory stimuli. Interestingly, among the significant values of correlation found in AT, the coatomer protein complex subunit alpha (COPA) and the solute carrier family 11 member 2 (SLC11A2, also known as natural resistance-associated macrophage protein 2, or NRAMP2) showed positive correlation with TLR2, while the leptin receptor (LEPR) was associated with TLR3 gene expression in human AT (Table 6 and Fig. 5). Of note, COPA proteins are involved in the regulation of lipid droplet formation by establishing connections with the endoplasmic 
reticulum, allowing delocalization of enzymes involved in triacylglycerol metabolism [54, 55]. On the other hand, SLC11A2 participates in the regulation of cellular iron metabolism [56], leading to the proper functioning and activation of AT macrophages [57]. Regarding AT/ adipocytes TLR3, the association of LEPR points out important insights into regulatory

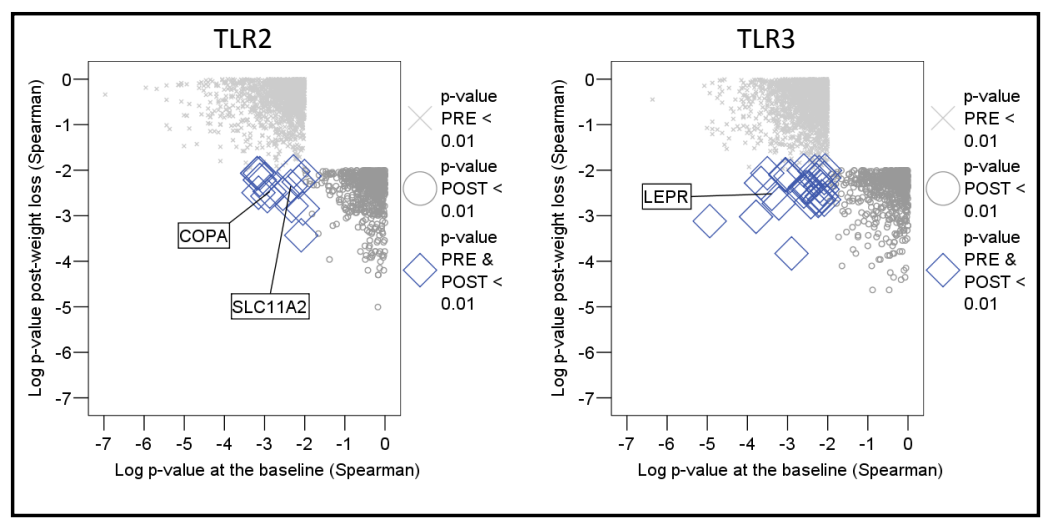

Fig. 5. Plots showing correlation between TLR2 and TLR3 mRNA and the expression levels assessed for other coding and non-coding RNAs measured by microarray in human adipose tissue of 16 women at the baseline (PRE) and 2-years after gastric bypass (POST) [35]. COPA: coatomer protein complex subunit alpha, SLC11A2: solute carrier family 11 member 2, LEPR: leptin receptor.

mechanisms leading to inflammation, metabolism and immune disorders conducted through changes in fat cells [58]. In line with this, Strodthoff et al. [18] provided evidence showing that TLR3 regulates glucose metabolism though the modulation of insulin levels but not by changes in weight or peripheral insulin sensitivity. To determine whether TLR3 is linked to metabolic inflammation beyond fatty acids and glucose modulation of other TLR, these authors investigated physiological changes in Tlr $3^{---}$mice and the impact of genetic variants affecting TLR3 and insulin-related traits. They concluded that the absence of functional TLR3 "protects" against metabolic disturbances due to changes in fat intake and lipid metabolism, in spite of the systemic inflammation found in Tlr $3 \%$ mice [18]. On the other hand, Poly(I:C) enhanced the differentiation of in vitro cultured mesenchymal stem cells towards lipidcontaining mature adipocytes [59]. Current dissection of tissue-specific obesity-related inflammation and insulin resistance in human AT shows decreased TLR3 in adipocytes, which is linked to decreased leptin receptor in obese/ inflamed states that may influence glucose homeostasis and fatty acid metabolism, as further demonstrated by treatments with agonists of TLR3. Thereby, decreased TLR3 in obese adipocytes may disrupt the response to double-stranded RNA and the synthesis of molecules that are involved in the regulation and maintenance of the differentiation state, together with the immunosuppressive capacity of mature adipocytes and precursor stem cells [60].

\section{Dynamic changes in TLR are related to cell type and the activation state}

Although tissue and blood-based transcriptomics research has great potential in clinical applications, it has its own set of limitations. For instance, whole blood and tissue sampling introduces cell distribution and variations in cell population. Thus, the dynamic composition of heterogenic samples in response to environmental fluctuations or disease may exhibit some degree of variability not representative for molecular changes in cells itself. Endorsement of results from different experimental designs and samples may overlap this handicap. Thereby, while specific features of inter-individual variation in gene expression patterns could be traced to variation in percent of cell subsets $[42,61]$, other features may be related to changes in metabolism and the state of activation of specific cells [44]. Fat depots are in a constant flux with changing cellular populations. Obesity can tip the scale towards the accumulation of certain cell populations and the dysregulation of others. For example, circulating immune cells such as macrophages, lymphocytes, and neutrophils are found composing the stromal-vascular cell (SVC) fraction [62], and are believed to promote the local inflammation and deleterious consequences of an hyperplastic AT [44]. In obesity, 


\section{Cellular Physiology Cell Physiol Biochem 2018;51:1051-1068 \begin{tabular}{ll|l} 
and Biochemistry & $\begin{array}{l}\text { DOl: 10.1159/000495487 } \\
\text { Published online: } 24 \text { November } 2018\end{array}$ & $\begin{array}{l}\text { ( } 2018 \text { The Author(s). Published by S. Karger AG, Basel } \\
\text { wwwer.com/cpb }\end{array}$ \\
\cline { 2 - 3 }
\end{tabular}}

AT macrophages content increases from $10-15 \%$ to $50-60 \%$ of SVC total cells and is higher in visceral than in subcutaneous AT, consistent with the hypothesis that visceral fat plays a more prominent role in insulin resistance and inflammation [63]. In agreement with this, the magnitude of obesity-induced up-regulation of many TLR was greater in visceral than in subcutaneous AT, affecting both diet and genetically-induced obese mice [3], and being related to weight and the degree of inflammation and metabolic impairment. Precisely, the dynamic changes seen in TLR expressed by obese/ inflamed AT of men and mice can be referred to as the AT remodeling during the course of obesity, in which SVC change dramatically in number and cell type, turning into proinflammatory signaling cascades. In this context, changes in the expression of TLR found in human AT, especially during obesity-related chronic immune activation and the surgery-induced acute inflammation reflected by increased TLR1, TLR2 and TLR8, were more likely linked to cells from SVC, and were more prominent in VAT than in SAT, while decreased TLR3 in obese SAT depicted biological variations affecting differentiated adipocytes as the most prevalent cellular specie in this depot. Also of interest, the dynamic changes mirrored by results assessed in different samples indicate the close association of whole blood and AT TLR3 measures with lymphocytes, pointing out a unique feature of this TLR. Trying to endorse this concept, we evaluated Spearman's $r$ and p-values derived from measures of the level of significance in correlations detected between AT TLR gene candidates and microarray expressions values. The computed significant values of correlation at the baseline and after weight loss identified a list of 15 and 28 coding and noncoding transcripts associated with TLR2 and TLR3, respectively (Table 6). Here, SAT TLR3 measures correlated with the expression of $\mathrm{T}$ cell surface receptors and major lymphocyte specification factors such as FOXP3, TRAV8-1 (inversely), and TRAJ2 (directly associated). Noteworthy, decreases in regulatory T cell population have been previously reported in VAT of genetically obese mice, being opposite to the macrophage number, inflammation, and metabolic impairment $[64,65]$.

\section{Conclusion}

We confirm significant fluctuations in TLR patterns in human AT, namely visceral TLR1, 2, 3, 5, 7, and 8, which are associated with inflammatory and metabolic issues linked to obese AT. While TLR1 and 8 seem to be linked to the composition of the SVC fraction, specific stress-related changes affecting the expression levels of TLR2 and 3 in adipocytes have been identified in all samples. The observation is in concordance with previous studies demonstrating that increased expression of all TLR but TLR3 is linked to diet-induced obese AT, in close association with inflammation and decreased insulin sensitivity [3]. Thus, beside their defense function of alerting immune system of the presence of microorganisms, TLR being expressed in energy-storage cells such as adipocytes may be of great interest for the understanding of metabolic inflammation and associated diseases. Current data point out the decreased expression of TLR3 in adipocytes at the forefront of changes affecting AT homeostasis in obesity-associated inflammatory states. Obviously, this conclusion needs to be further endorsed in additional follow-up studies including the interplay of strain and race/ethnicity in the innate immune response to the risk of impaired metabolism under conditions that elicit diminished TLR3 in fat cells. However, from a clinical point of view, our results represent new insight regarding the role of TLR regulation in AT for further reinforce the dynamic mechanisms linking inflammation and metabolism, which might reveal future novel therapeutic targets. 


\section{Cellular Physiology Cell Physiol Biochem 2018;51:1051-1068

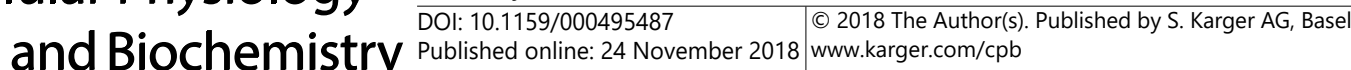

Latorre et al.: TLR3 and Metabolic Inflammation

\section{Acknowledgements}

This work was partially supported by the CIBER de la Fisiopatología de la Obesidad y la Nutrición (CIBEROBN) and the Fondo Europeo de Desarrollo Regional (FEDER), and by grants from the Govern de la Generalitat (Pla Estratègic de Recerca i Innovació en Salut, PERIS 2016) and from the Fundació La Marató de TV3 (440/C/2016) (to FJO), and also a predoctoral fellowship (AGAUR FI-DGR 2015) from the Agència de Gestió d'Ajuts Universitaris de Recerca (to JL). The CIBEROBN is an initiative from the Instituto de Salud Carlos III (ISCIII). We want also acknowledge the patients, the FATBANK platform promoted by the CIBEROBN and the IDIBGI Biobank (Biobanc IDIBGI, B.0000872), integrated in the Spanish National Biobanks Network, for their collaboration and coordination. All authors of this manuscript have participated in the execution of the study, and we certify that there is nothing to disclose regarding the material discussed in this manuscript. FJO designed the study, analysed the biochemical variables, performed the statistical analysis, and wrote the manuscript. JL, JMM-N, MS, and MB analysed biochemical variables. JIR-H, JG, JMF, RV, RS, and WR obtained human fat and blood samples, anthropometrical characteristics, and the written consent of participants. JMF-R revised the manuscript and provided important intellectual content. All authors are aware of and agree to the content of the manuscript, and have approved the final version and their being listed as an author on the manuscript. The contents of this manuscript have not been copyrighted or published previously elsewhere. Neither this manuscript nor any similar manuscript, in whole or in part, will be copyrighted, submitted, or published elsewhere by one or more authors of this manuscript.

\section{Disclosure Statement}

No conflict of interests exists.

\section{References}

1 Cook DN, Pisetsky DS, Schwartz DA: Toll-like receptors in the pathogenesis of human disease. Nat Immunol 2004;5:975-979.

2 Dasu MR, Devaraj S, Park S, Jialal I: Increased toll-like receptor (TLR) activation and TLR ligands in recently diagnosed type 2 diabetic subjects. Diabetes Care 2010;33:861-868.

- Kim SJ, Choi Y, Choi YH, Park T: Obesity activates toll-like receptor-mediated proinflammatory signaling cascades in the adipose tissue of mice. J Nutr Biochem 2012;23:113-122.

4 Manuzak J, Dillon S, Wilson C: Differential interleukin-10 (IL-10) and IL-23 production by human blood monocytes and dendritic cells in response to commensal enteric bacteria. Clin Vaccine Immunol 2012;19:1207-1217.

5 Wykes MN, Liu XQ, Jiang S, Hirunpetcharat C, Good MF: Systemic tumor necrosis factor generated during lethal Plasmodium infections impairs dendritic cell function. J Immunol 2007;179:3982-3987.

-6 Zuberi RI, Ge XN, Jiang S, Bahaie NS, Kang BN, Hosseinkhani RM, Frenzel EM, Fuster MM, Esko JD, Rao SP, Sriramarao P: Deficiency of endothelial heparan sulfates attenuates allergic airway inflammation. J Immunol 2009;183:3971-3979.

7 Delzenne NM, Neyrinck AM, Backhed F, Cani PD: Targeting gut microbiota in obesity: effects of prebiotics and probiotics. Nat Rev Endocrinol 2011;7:639-646.

-8 Lombardo E, DelaRosa 0, Mancheno-Corvo P, Menta R, Ramirez C, Buscher D: Toll-like receptor-mediated signaling in human adipose-derived stem cells: implications for immunogenicity and immunosuppressive potential. Tissue Eng Part A 2009;15:1579-1589.

-9 Pietsch J, Batra A, Stroh T, Fedke I, Glauben R, Okur B, Zeitz M, Siegmund B: Toll-like receptor expression and response to specific stimulation in adipocytes and preadipocytes: on the role of fat in inflammation. Ann N Y Acad Sci 2006;1072:407-409. 


\section{Cellular Physiology Cell Physiol Biochem 2018:51:1051-1068 and Biochemistry \begin{tabular}{l|l|l} 
DOI: 10.1159/000495487 & (c) 2018 The Author(s). Published by S. Karger AG, Basel
\end{tabular}

10 Medzhitov R, Preston-Hurlburt P, Janeway CA, Jr.: A human homologue of the Drosophila Toll protein signals activation of adaptive immunity. Nature 1997;388:394-397.

11 Fresno M, Alvarez R, Cuesta N: Toll-like receptors, inflammation, metabolism and obesity. Arch Physiol Biochem 2011;117:151-164.

-12 Baccala R, Hoebe K, Kono DH, Beutler B, Theofilopoulos AN: TLR-dependent and TLR-independent pathways of type I interferon induction in systemic autoimmunity. Nat Med 2007;13:543-551.

13 Akira S, Uematsu S, Takeuchi O: Pathogen recognition and innate immunity. Cell 2006;124:783-801.

14 Zahringer U, Lindner B, Inamura S, Heine H, Alexander C: TLR2 - promiscuous or specific? A critical reevaluation of a receptor expressing apparent broad specificity. Immunobiology 2008;213:205-224.

15 Caricilli AM, Nascimento PH, Pauli JR, Tsukumo DM, Velloso LA, Carvalheira JB, Saad MJ: Inhibition of tolllike receptor 2 expression improves insulin sensitivity and signaling in muscle and white adipose tissue of mice fed a high-fat diet. J Endocrinol 2008;199:399-406.

16 Ehses JA, Meier DT, Wueest S, Rytka J, Boller S, Wielinga PY, Schraenen A, Lemaire K, Debray S, Van Lommel L, Pospisilik JA, Tschopp O, Schultze SM, Malipiero U, Esterbauer H, Ellingsgaard H, Rutti S, Schuit FC, Lutz TA, Boni-Schnetzler $\mathrm{M}$ et al.: Toll-like receptor 2-deficient mice are protected from insulin resistance and beta cell dysfunction induced by a high-fat diet. Diabetologia 2010;53:1795-1806.

17 Ahmad R, Al-Mass A, Atizado V, Al-Hubail A, Al-Ghimlas F, Al-Arouj M, Bennakhi A, Dermime S, Behbehani K: Elevated expression of the toll like receptors 2 and 4 in obese individuals: its significance for obesityinduced inflammation. J Inflamm (Lond) 2012;9:48.

-18 Strodthoff D, Ma Z, Wirstrom T, Strawbridge RJ, Ketelhuth DF, Engel D, Clarke R, Falkmer S, Hamsten A, Hansson GK, Bjorklund A, Lundberg AM: Toll-Like Receptor 3 Influences Glucose Homeostasis and betaCell Insulin Secretion. Diabetes 2015;64:3425-3438.

19 Saad MJ, Santos A, Prada PO: Linking Gut Microbiota and Inflammation to Obesity and Insulin Resistance. Physiology (Bethesda) 2016;31:283-293.

20 Sindhu S, Al-Roub A, Koshy M, Thomas R, Ahmad R: Palmitate-Induced MMP-9 Expression in the Human Monocytic Cells is Mediated through the TLR4-MyD88 Dependent Mechanism. Cell Physiol Biochem 2016;39:889-900.

-21 Kochumon S, Wilson A, Chandy B, Shenouda S, Tuomilehto J, Sindhu S, Ahmad R: Palmitate Activates CCL4 Expression in Human Monocytic Cells via TLR4/MyD88 Dependent Activation of NF-kappaB/MAPK/ PI3K Signaling Systems. Cell Physiol Biochem 2018;46:953-964.

22 Ahmad R, Al-Roub A, Kochumon S, Akther N, Thomas R, Kumari M, Koshy MS, Tiss A, Hannun YA, Tuomilehto J, Sindhu S, Rosen ED: The Synergy between Palmitate and TNF-alpha for CCL2 Production Is Dependent on the TRIF/IRF3 Pathway: Implications for Metabolic Inflammation. J Immunol 2018;200:3599-3611.

23 Shi H, Kokoeva MV, Inouye K, Tzameli I, Yin H, Flier JS: TLR4 links innate immunity and fatty acid-induced insulin resistance. J Clin Invest 2006;116:3015-3025.

24 Kolek MJ, Carlquist JF, Muhlestein JB, Whiting BM, Horne BD, Bair TL, Anderson JL: Toll-like receptor 4 gene Asp299Gly polymorphism is associated with reductions in vascular inflammation, angiographic coronary artery disease, and clinical diabetes. Am Heart J 2004;148:1034-1040.

25 Savva A, Roger T: Targeting toll-like receptors: promising therapeutic strategies for the management of sepsis-associated pathology and infectious diseases. Front Immunol 2013;4:387.

26 Rocha DM, Caldas AP, Oliveira LL, Bressan J, Hermsdorff HH: Saturated fatty acids trigger TLR4-mediated inflammatory response. Atherosclerosis 2016;244:211-215.

27 Ashkar AA, Rosenthal KL: Toll-like receptor 9, CpG DNA and innate immunity. Curr Mol Med 2002;2:545556.

28 Gorden KB, Gorski KS, Gibson SJ, Kedl RM, Kieper WC, Qiu X, Tomai MA, Alkan SS, Vasilakos JP: Synthetic TLR agonists reveal functional differences between human TLR7 and TLR8. J Immunol 2005;174:12591268.

29 Hemmi H, Kaisho T, Takeuchi O, Sato S, Sanjo H, Hoshino K, Horiuchi T, Tomizawa H, Takeda K, Akira S: Small anti-viral compounds activate immune cells via the TLR7 MyD88-dependent signaling pathway. Nat Immunol 2002;3:196-200.

-30 Ahmad R, Kochumon S, Thomas R, Atizado V, Sindhu S: Increased adipose tissue expression of TLR8 in obese individuals with or without type-2 diabetes: significance in metabolic inflammation. J Inflamm (Lond) 2016;13:38. 


\section{Cellular Physiology Cell Physiol Biochem 2018;51:1051-1068

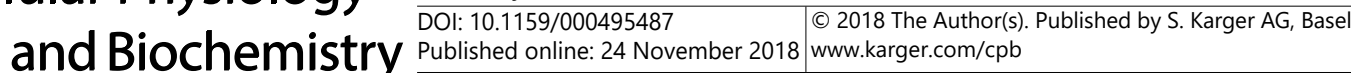

31 Jiang S, Li X, Hess NJ, Guan Y, Tapping RI: TLR10 Is a Negative Regulator of Both MyD88-Dependent and -Independent TLR Signaling. J Immunol 2016;196:3834-3841.

-32 Sindhu S, Akhter N, Kochumon S, Thomas R, Wilson A, Shenouda S, Tuomilehto J, Ahmad R: Increased Expression of the Innate Immune Receptor TLR10 in Obesity and Type-2 Diabetes: Association with ROSMediated Oxidative Stress. Cell Physiol Biochem 2018;45:572-590.

-33 Fernandez-Real JM, Pickup JC: Innate immunity, insulin resistance and type 2 diabetes. Diabetologia 2012;55:273-278.

-34 Iyer A, Brown L, Whitehead JP, Prins JB, Fairlie DP: Nutrient and immune sensing are obligate pathways in metabolism, immunity, and disease. Faseb J 2015;29:3612-3625.

35 Ortega FJ, Mercader JM, Moreno-Navarrete JM, Nonell L, Puigdecanet E, Rodriquez-Hermosa JI, Rovira O, Xifra G, Guerra E, Moreno M, Mayas D, Moreno-Castellanos N, Fernandez-Formoso JA, Ricart W, Tinahones FJ, Torrents D, Malagon MM, Fernandez-Real JM: Surgery-Induced Weight Loss Is Associated With the Downregulation of Genes Targeted by MicroRNAs in Adipose Tissue. J Clin Endocrinol Metab 2015;100:E1467-1476.

-36 Ortega FJ, Vilallonga R, Xifra G, Sabater M, Ricart W, Fernandez-Real JM: Bariatric surgery acutely changes the expression of inflammatory and lipogenic genes in obese adipose tissue. Surg Obes Relat Dis 2016;12:357-362.

-37 Bunnell BA, Flaat M, Gagliardi C, Patel B, Ripoll C: Adipose-derived stem cells: isolation, expansion and differentiation. Methods 2008;45:115-120.

-38 Bassols J, Ortega FJ, Moreno-Navarrete JM, Peral B, Ricart W, Fernandez-Real JM: Study of the proinflammatory role of human differentiated omental adipocytes. J Cell Biochem 2009;107:1107-1117.

-39 Burczynski ME, Dorner AJ: Transcriptional profiling of peripheral blood cells in clinical pharmacogenomic studies. Pharmacogenomics 2006;7:187-202.

-40 Caimari A, Oliver P, Keijer J, Palou A: Peripheral blood mononuclear cells as a model to study the response of energy homeostasis-related genes to acute changes in feeding conditions. Omics 2010;14:129-141.

41 Caimari A, Oliver P, Rodenburg W, Keijer J, Palou A: Slc27a2 expression in peripheral blood mononuclear cells as a molecular marker for overweight development. Int J Obes (Lond) 2010;34:831-839.

42 Mohr S, Liew CC: The peripheral-blood transcriptome: new insights into disease and risk assessment. Trends Mol Med 2007;13:422-432.

43 Chaussabel D: Assessment of immune status using blood transcriptomics and potential implications for global health. Semin Immunol 2010;27:58-66.

-44 Capel F, Klimcakova E, Viguerie N, Roussel B, Vitkova M, Kovacikova M, Polak J, Kovacova Z, Galitzky J, Maoret JJ, Hanacek J, Pers TH, Bouloumie A, Stich V, Langin D: Macrophages and adipocytes in human obesity: adipose tissue gene expression and insulin sensitivity during calorie restriction and weight stabilization. Diabetes 2009;58:1558-1567.

45 Xu H, Barnes GT, Yang Q Tan G, Yang D, Chou CJ, Sole J, Nichols A, Ross JS, Tartaglia LA, Chen H: Chronic inflammation in fat plays a crucial role in the development of obesity-related insulin resistance. J Clin Invest 2003;112:1821-1830.

-46 Woolard MD, Kevil CG: Paying the Toll for Glucose Regulation: A Central Role for TLR3. Diabetes 2015;64:3345-3346.

47 Gay NJ, Symmons MF, Gangloff M, Bryant CE: Assembly and localization of Toll-like receptor signalling complexes. Nat Rev Immunol 2014;14:546-558.

48 Elgazar-Carmon V, Rudich A, Hadad N, Levy R: Neutrophils transiently infiltrate intra-abdominal fat early in the course of high-fat feeding. J Lipid Res 2008;49:1894-1903.

49 Kintscher U, Hartge M, Hess K, Foryst-Ludwig A, Clemenz M, Wabitsch M, Fischer-Posovszky P, Barth TF, Dragun D, Skurk T, Hauner H, Bluher M, Unger T, Wolf AM, Knippschild U, Hombach V, Marx N: T-lymphocyte infiltration in visceral adipose tissue: a primary event in adipose tissue inflammation and the development of obesity-mediated insulin resistance. Arterioscler Thromb Vasc Biol 2008;28:1304-1310.

50 Weisberg SP, McCann D, Desai M, Rosenbaum M, Leibel RL, Ferrante AW, Jr.: Obesity is associated with macrophage accumulation in adipose tissue. J Clin Invest 2003;112:1796-1808.

51 O’Hara A, Lim FL, Mazzatti DJ, Trayhurn P: Microarray analysis identifies matrix metalloproteinases (MMPs) as key genes whose expression is up-regulated in human adipocytes by macrophage-conditioned medium. Pflugers Arch 2009;458:1103-1114. 


\section{Cellular Physiology Cell Physiol Biochem 2018:51:1051-1068

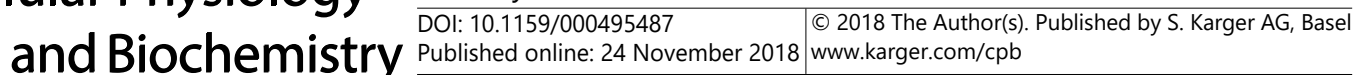

52 Dasu MR, Devaraj S, Zhao L, Hwang DH, Jialal I: High glucose induces toll-like receptor expression in human monocytes: mechanism of activation. Diabetes 2008;57:3090-3098.

53 Jiang SY, Wei CC, Shang TT, Lian Q Wu CX, Deng JY: High glucose induces inflammatory cytokine through protein kinase $\mathrm{C}$-induced toll-like receptor 2 pathway in gingival fibroblasts. Biochem Biophys Res Commun 2012;427:666-670.

54 Wilfling F, Thiam AR, Olarte MJ, Wang J, Beck R, Gould TJ, Allgeyer ES, Pincet F, Bewersdorf J, Farese RV, Jr., Walther TC: Arf1/COPI machinery acts directly on lipid droplets and enables their connection to the ER for protein targeting. Elife 2014;3:e01607.

-55 Wilfling F, Wang H, Haas JT, Krahmer N, Gould TJ, Uchida A, Cheng JX, Graham M, Christiano R, Frohlich F, Liu X, Buhman KK, Coleman RA, Bewersdorf J, Farese RV, Jr., Walther TC: Triacylglycerol synthesis enzymes mediate lipid droplet growth by relocalizing from the ER to lipid droplets. Dev Cell 2013;24:384-399.

56 Chua AC, Graham RM, Trinder D, Olynyk JK: The regulation of cellular iron metabolism. Crit Rev Clin Lab Sci 2007;44:413-459.

57 Hubler MJ, Peterson KR, Hasty AH: Iron homeostasis: a new job for macrophages in adipose tissue? Trends Endocrinol Metab 2015;26:101-109.

58 Abella V, Scotece M, Conde J, Pino J, Gonzalez-Gay MA, Gomez-Reino JJ, Mera A, Lago F, Gomez R, Gualillo O: Leptin in the interplay of inflammation, metabolism and immune system disorders. Nat Rev Rheumatol 2017;13:100-109.

59 Chen X, Zhang ZY, Zhou H, Zhou GW: Characterization of mesenchymal stem cells under the stimulation of Toll-like receptor agonists. Dev Growth Differ 2014;56:233-244.

-60 Waterman RS, Tomchuck SL, Henkle SL, Betancourt AM: A new mesenchymal stem cell (MSC) paradigm: polarization into a pro-inflammatory MSC1 or an Immunosuppressive MSC2 phenotype. PLoS One 2010;5:e10088.

-61 Whitney AR, Diehn M, Popper SJ, Alizadeh AA, Boldrick JC, Relman DA, Brown PO: Individuality and variation in gene expression patterns in human blood. Proc Natl Acad Sci U S A 2003;100:1896-1901.

62 Ortega FJ, Fernandez-Real JM: Inflammation in adipose tissue and fatty acid anabolism: when enough is enough! Horm Metab Res 2013;45:1009-1019.

63 Kamei N, Tobe K, Suzuki R, Ohsugi M, Watanabe T, Kubota N, Ohtsuka-Kowatari N, Kumagai K, Sakamoto K, Kobayashi M, Yamauchi T, Ueki K, Oishi Y, Nishimura S, Manabe I, Hashimoto H, Ohnishi Y, Ogata H, Tokuyama K, Tsunoda M et al.: Overexpression of monocyte chemoattractant protein-1 in adipose tissues causes macrophage recruitment and insulin resistance. J Biol Chem 2006;281:26602-26614.

-64 Feuerer M, Herrero L, Cipolletta D, Naaz A, Wong J, Nayer A, Lee J, Goldfine AB, Benoist C, Shoelson S, Mathis D: Lean, but not obese, fat is enriched for a unique population of regulatory $\mathrm{T}$ cells that affect metabolic parameters. Nat Med 2009;15:930-939.

65 Cipolletta D, Feuerer M, Li A, Kamei N, Lee J, Shoelson SE, Benoist C, Mathis D: PPAR-gamma is a major driver of the accumulation and phenotype of adipose tissue Treg cells. Nature 2012;486:549-553. 